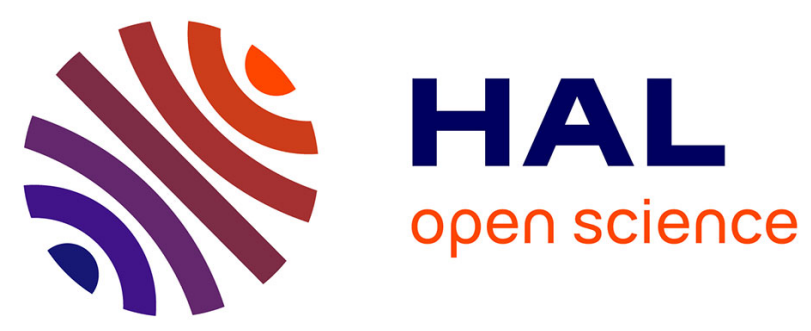

\title{
Dynamic behavior of a Mechanically Stabilized Earth wall under harmonic loading: Experimental characterization and 3D finite elements model
} Jean-Baptiste Payeur, Alain Corfdir, Emmanuel Bourgeois

\section{- To cite this version:}

Jean-Baptiste Payeur, Alain Corfdir, Emmanuel Bourgeois. Dynamic behavior of a Mechanically Stabilized Earth wall under harmonic loading: Experimental characterization and 3D finite elements model. Computers and Geotechnics, 2015, 65, pp.199 - 211. 10.1016/j.compgeo.2014.12.001 . hal01768236

\section{HAL Id: hal-01768236 \\ https://hal-enpc.archives-ouvertes.fr/hal-01768236}

Submitted on 17 Apr 2018

HAL is a multi-disciplinary open access archive for the deposit and dissemination of scientific research documents, whether they are published or not. The documents may come from teaching and research institutions in France or abroad, or from public or private research centers.
L'archive ouverte pluridisciplinaire HAL, est destinée au dépôt et à la diffusion de documents scientifiques de niveau recherche, publiés ou non, émanant des établissements d'enseignement et de recherche français ou étrangers, des laboratoires publics ou privés. 


\section{Dynamic behavior of a Mechanically Stabilized Earth wall under harmonic loading: experimental characterization and 3D finite elements model.}

Jean-Baptiste PAYEUR ${ }^{1}$, Alain CORFDIR ${ }^{1}$, Emmanuel BOURGEOIS $^{2}$

${ }^{1}$ Université Paris-Est, Laboratoire Navier

Ecole des Ponts ParisTech

6-8 avenue Blaise Pascal, Cité Descartes, Champs-sur-Marne

77455 Marne-la-Vallée, France

payeurj@cermes.enpc.fr

corfdir@cermes.enpc.fr

${ }^{2}$ Université Paris-Est, IFSTTAR-

14-20 Boulevard Newton

Cité Descartes, Champs sur Marne

F-77447 Marne la Vallée Cedex 2, France

emmanuel.bourgeois@ifsttar.fr

Corresponding author:

Jean-Baptiste PAYEUR

Université Paris-Est, Laboratoire Navier

Ecole des Ponts ParisTech

6-8 avenue Blaise Pascal, Cité Descartes, Champs-sur-Marne

77455 Marne-la-Vallée, France

payeurj@cermes.enpc.fr

+33164153539

Published as : Payeur, J.-B., Corfdir, A., \& Bourgeois, E. (2015). Dynamic behavior of a Mechanically Stabilized Earth wall under harmonic loading: Experimental characterization and 3D finite elements model. Computers and Geotechnics, 65, 199-211. doi:10.1016/j.compgeo.2014.12.001 


\begin{abstract}
This article presents an analysis of a full-scale experimental Mechanically Stabilized Earth (MSE) wall under harmonic loading. Experimental results are shown and discussed, and compared with 3D finite element simulations. The experimental results indicate that the embankment behavior is linear, and that the displacements of the wall, the tensile forces in the reinforcements, and the stresses in the backfill material are strongly frequency-dependent. The numerical analysis is performed in the time domain with Rayleigh damping and includes special modeling strategies to represent the facing, the ground-reinforcement interface and the overburden pressure. Experimental and numerical values are found to be in good agreement.
\end{abstract}




\section{Introduction}

Mechanically Stabilized Earth (MSE) walls are often used in common civil engineering structures, especially in roadways infrastructures or conventional railways as well. Nevertheless only few of them have been built for High Speed Trains (HST) railways, and one can wonder what would be the dynamic response of a MSE structure under loading caused by HST passage. Effects of trains passing on railways are well known and presented in several publications dealing with track behavior [1], [2], often focused on ballast [3], [4], [5] or sleepers [6] or more generally with the response of the surrounding environment [7], [8]. Nevertheless, the specificities of MSE walls used for HST railways are not taken into account in these states of the art.

On the other hand, several aspects of MSE behavior are well known from now, since this material was invented by Henri Vidal in 1963: either fundamental aspects like static analysis experimentations [9], pull-off tests [10] or more specific investigations like analyzing the impact of corrosion on steel strips of MSE wall [11]. From a numerical point of view, special attention has been paid to develop good practices in modeling MSE walls, using finite elements models (for example [12], [13]) or finite differences models [14] as well, under several static loading conditions, or to model pull-out tests.

Special investigations have also been performed to estimate the seismic response of similar structures under earthquake, with the help of full-scale experimentation [15], centrifuge models [15], reduced scale models [16] or more conveniently 2D-FEM models like in [17], [18], [19]. According to parametric studies based on realistic walls geometry, these authors pointed out that the response of a reinforced wall to an earthquake was strongly linked with the geometry of the embankment, the material properties, as well as the earthquake motion.

Although some full scale investigations on MSE walls have been performed decades ago [20] or more recently [21] to study the influence of train loading on MSE, only few (2D) numerical model have been proposed [14] to explain the obtained results. This lack of consistent models is even more regrettable because all of these authors have found that dynamic effects have a significant influence on the reinforcement-ground interaction.

Then, from results both from seismic analysis of MSE walls and from experiments under dynamic loading, it has been found necessary to properly analyze the dynamic behavior of an MSE wall subjected to such loading, and then to propose a satisfying 3D model, able to describe the behavior of reinforced earth during the loading. The development of a 3D 
dynamic analysis should make it possible to get a better accuracy than the $2 \mathrm{D}$ models previously proposed either in [14], [17], [18] or [19].

To reach these two goals, a full scale experimental MSE railway embankment has been built in 2009 at the Large Scale Road Test Division (CER) of Rouen, and has been submitted to several static and dynamic loads. The experimental setup and some of the results have been presented in [21], and static analyses can be found in [12], [13]. The aim of this paper is to analyze the results obtained under dynamic loads and then to model the performed tests using 3D finite element simulations. The first part presents the experiment; the second part shows some of the results obtained, which highlight the dynamic behavior of the structure. Finally the numerical FEM model is presented, and the simulations are compared with the experiment. Displacements and velocities have been computed as functions of time, but results are presented in the frequency domain in order to compare them with experimental data. 


\section{Presentation of the full scale embankment}

\subsection{Geometry and materials}

To assess the performance of Mechanically Stabilized Earth walls under High Speed Train loading, a full-scale test on a model of railway embankment has been carried out at the Large Scale Road Test Division (CER) of Rouen (France) in 2009. This test was a part of a research program led by SNCF (the French National Railway Company), RFF (the owner of the French Railway Infrastructure) and IFSTTAR (French Institute of sciences and technology for transport, development and networks).

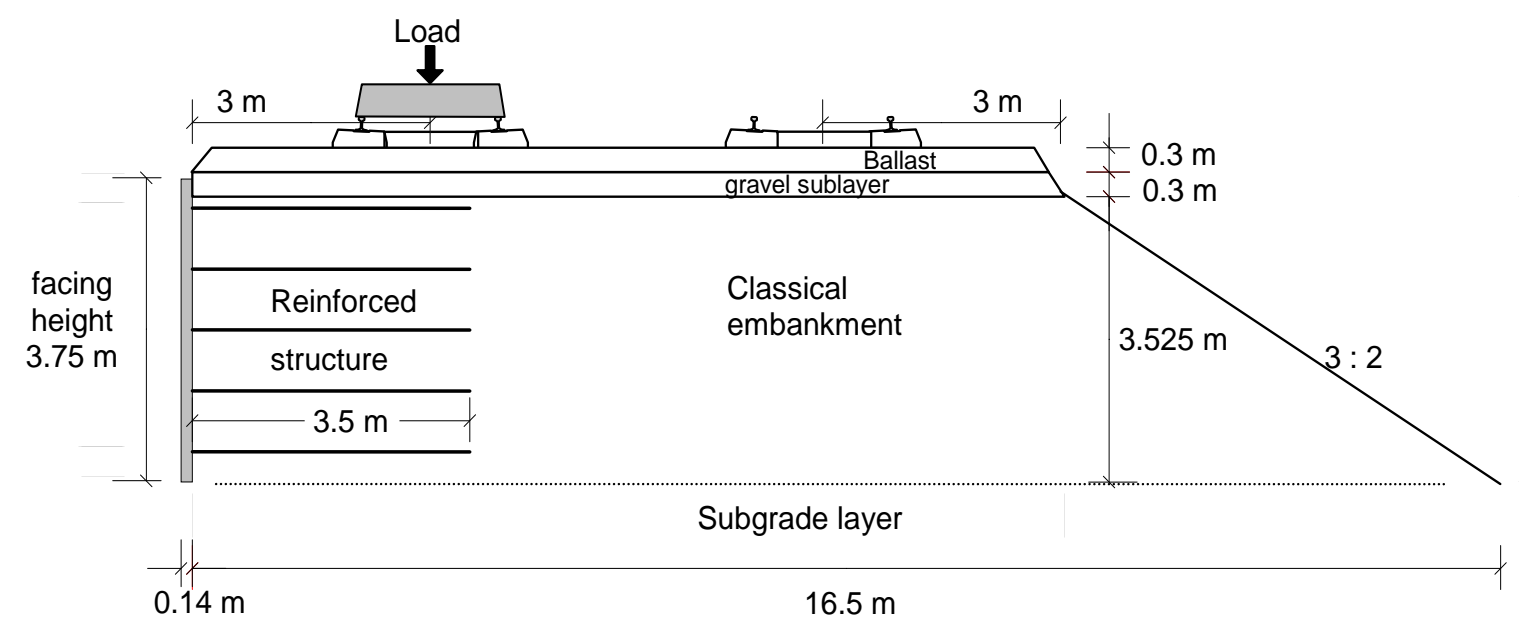

Figure 1 : Side view schematic of the experimental wall (after Bourgeois et al [13])

The whole structure consists in two embankments: a MSE structure (designed by the term Reinforced Structure or RS in this article) and a classical railway embankment (Classical Embankment or CE). It is built in an excavation limited by two parallels vertical concrete walls separated by a distance of $8 \mathrm{~m}$ and on a rigid subgrade layer. A schematic cross section 
of

the

structure

is

shown

in

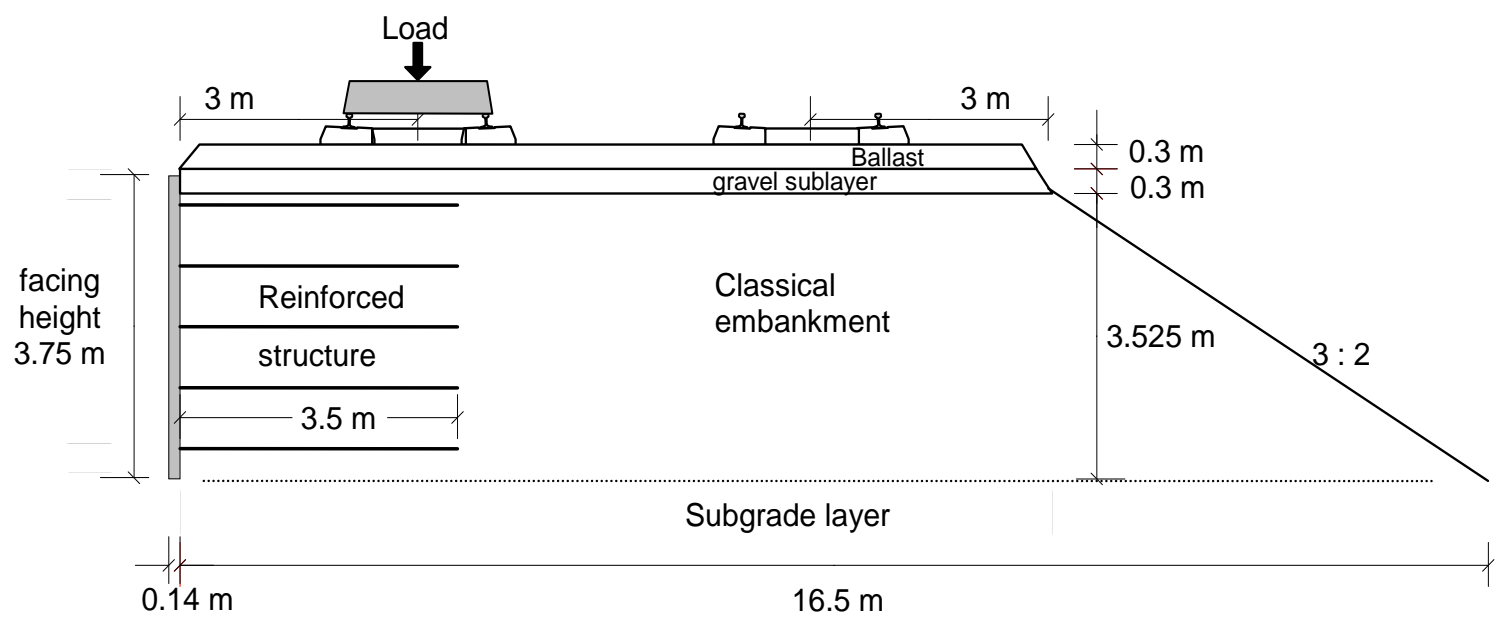

Figure 1.The embankment has been built in 10 layers; each of them compacted close to the Proctor optimum density. Each embankment is overlaid by a gravel sublayer, a ballast layer and one sleeper at the top. The sleepers are placed perpendicular to the facing and in the center between the concrete walls. They are $2.4 \mathrm{~m}$ long, $0.3 \mathrm{~m}$ wide and $0.27 \mathrm{~m}$ high. The sublayer is chosen from an untreated gravel material $(0 / 31.5 \mathrm{~mm})$, while ballast is a crushed and washed $31.5 / 50 \mathrm{~mm}$ material coming from the same quarry than sublayer material. Both materials comply with the specification of high-speed tracks, as recommended in [22].

The embankment material is a $40 \mathrm{~mm}$-sifted clayey gravel. The grain size is characterized by $\mathrm{d}_{50}=0.28 \mathrm{~mm}$ and $\mathrm{c}_{\mathrm{u}}=\mathrm{d}_{60} / \mathrm{d}_{10}=4.86$.

The wall facing consists in $1.5 \mathrm{~m} \times 1.5 \mathrm{~m}$ cross-shaped concrete panels. Four reinforcement strips of galvanized steel are connected to each panel. These strips are standard ribbed strips, $3.5 \mathrm{~m}$ long, $45 \mathrm{~mm}$ wide and $5 \mathrm{~mm}$ thick. Each strip has a reference number. This article sets the focus on the results obtained for strips \#36 and \#46 as shown in Figure 3 under the names of A36 and A46.

\subsection{Sensors installation}

An overall view of the sensors installation is shown in Figure 2.

Displacements sensors (LVDT) are placed close to the interface between the sublayer and the backfill, in order to monitor the vertical displacements of this interface during loading. Accelerometers are also located within the backfill bulk, close to the LVDT sensors. They only measure vertical accelerations. It is worth noting that a steel plate was laid at the sublayer-backfill interface, the LVDT sensors were placed within a cased wellbore and linked with the substratum taken as reference, as it is shown in Figure 4. 
Two vertical stresses sensors are located close to the \#46 strip providing values of vertical confining pressure during dynamic loading.

Strain gauges are glued on strips \#36 and \#46, as shown in Figure 2, measuring tensile forces within these reinforcements. In the following, the gauges are reset at the end of the MSE wall construction, and only incremental tensile forces are presented.

More details on the procedure followed to calibrate these sensors are available in [21].

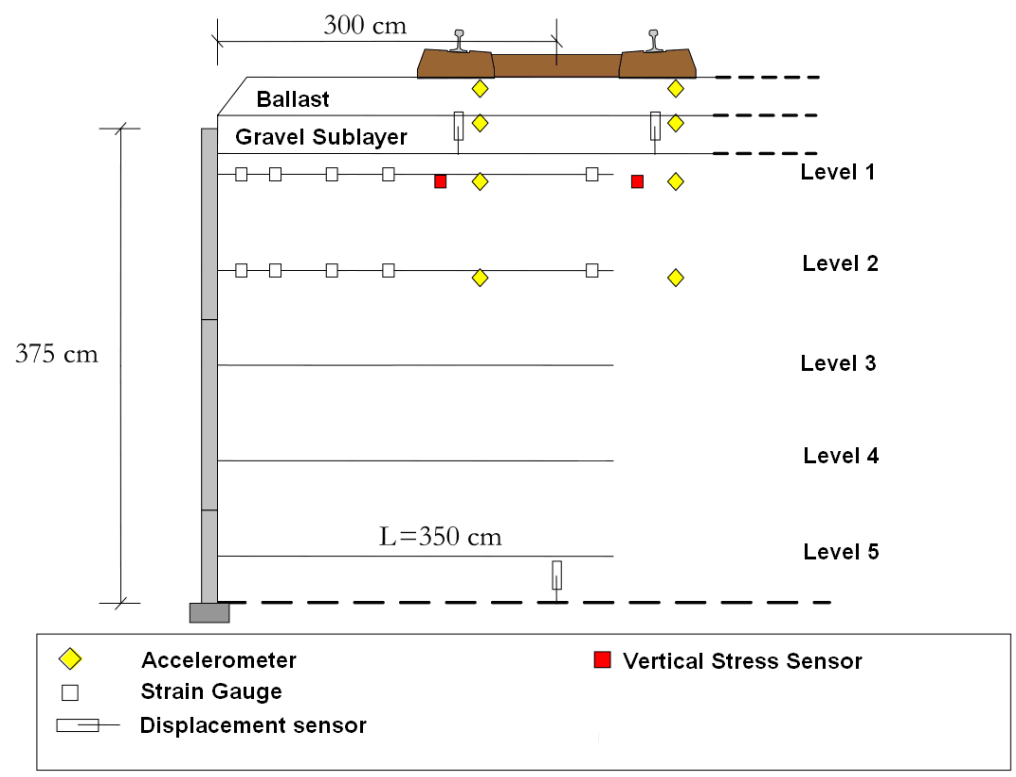

Figure 2 : Sensors distribution in the reinforced structure: side view. (after Soyez [21])

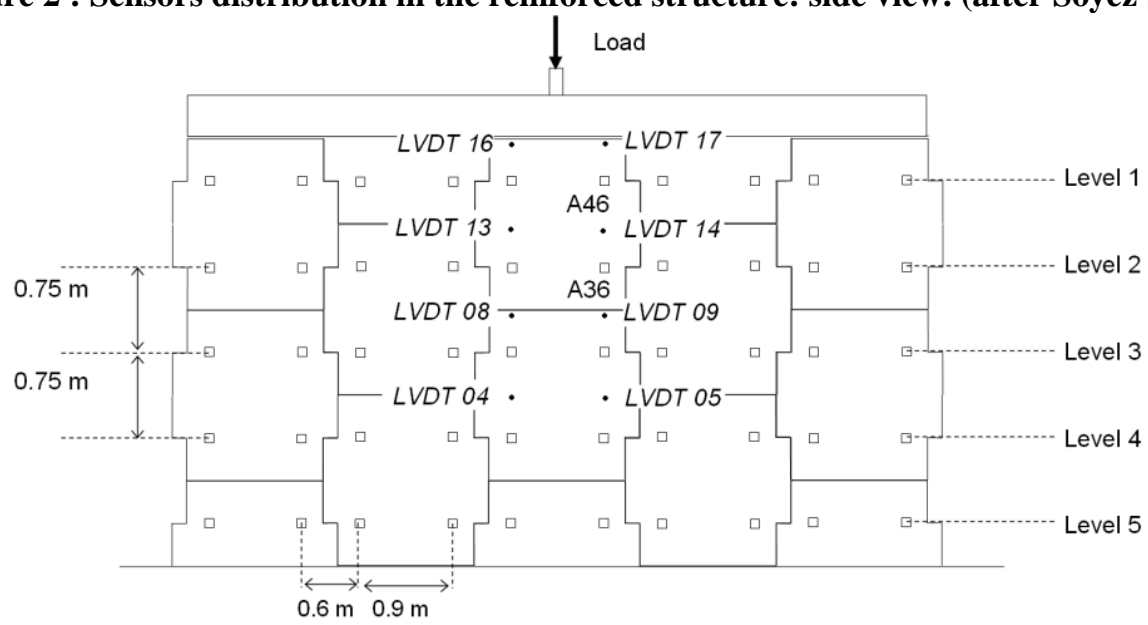

Figure 3 : Displacements sensors on the reinforced structure facing and monitored reinforcements (after Bourgeois et al. [13]) 


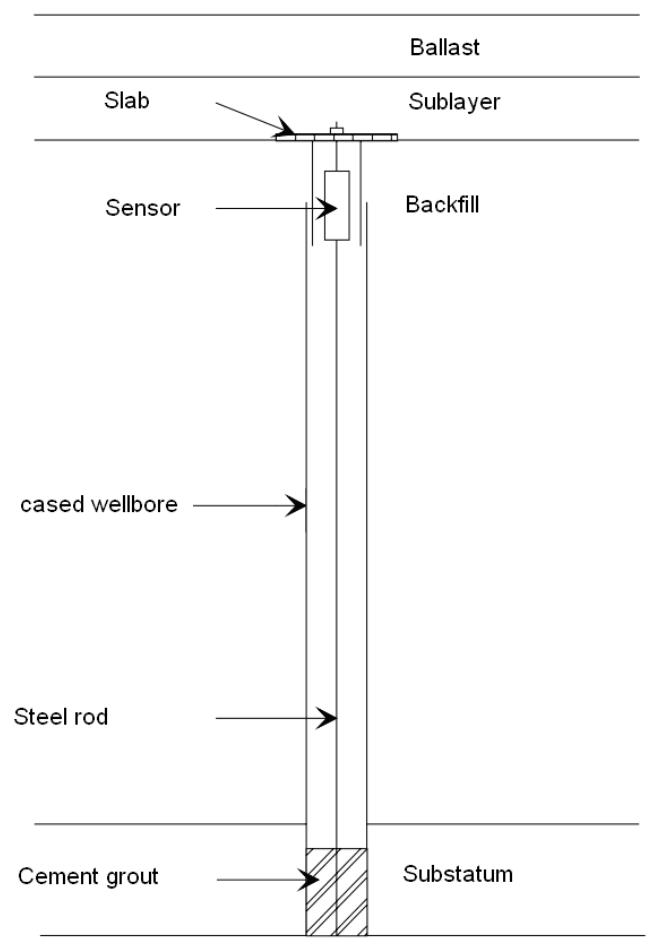

Figure 4 : Cased wellbore and displacements sensor at sublayer/backfill interface (after Soyez [21]) 


\subsection{Loading}

The sleepers have been loaded by a hydraulic jack applying a dynamic force on the top of each sleeper. First, static loads are applied, at 30, 60 and $90 \mathrm{kN}$. Then the embankment behavior under various dynamic loading sequences is analyzed. For each loading sequence, around 10,000 load cycles are applied either on the reinforced structure or on the classical embankment structure. This number of cycles allows studying the embankment modal behavior in established harmonic regime. Transient regime, delays or fatigue due to very high number of cycles is not presented in this article. Most of the results presented in part 3 are related to loadings on the RS sleeper, but some of them correspond also to a load applied on the CE sleeper.

As shown in Figure 5 (for three cycles), the applied load consists of a static part $F_{\text {mean }}$ (mean value of loading) and a harmonic part of amplitude $\Delta \mathrm{F}$. Two loading sequences have been led, for different values of $\mathrm{F}_{\text {mean }}$ and $\Delta \mathrm{F}$, as detailed in Table 1.

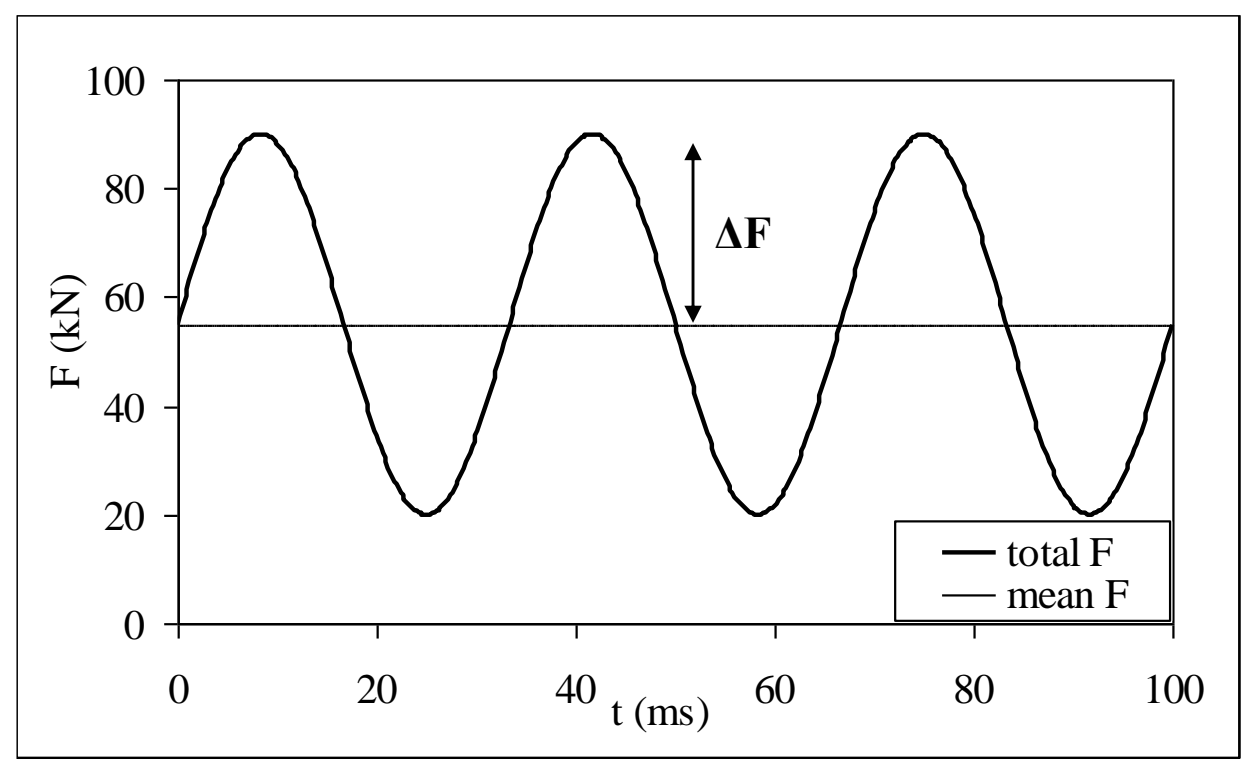

Figure 5 : Total and mean load applied on the sleeper at $30 \mathrm{~Hz}$.

The experimental setup made it possible to apply harmonic loads but not more complex loads associated to HST passing on rails.

For each loading sequence, several frequencies have been tested. They correspond to the first natural frequencies of the rail displacements due to HST passing for a speed up to 300 $\mathrm{km} / \mathrm{h}$. Their values are obtained by dividing the characteristic lengths of an HST wagon (bogie to bogie length, wheel to wheel length for one bogie, etc...), by its speed (more details about HST frequency characterization can be found in [6] or [8]). 
Such HST signature is for example shown in Figure 6 (taken from [8]), which shows the rail deflexion spectrum for a $300 \mathrm{~km} / \mathrm{h}$ passing HST. This figure does not take into consideration higher frequencies that may exist due to unevenness of wheels or rails (as presented in [23]). For the experimentation at the CER, it has been choosen to not consider frequencies higher than $35 \mathrm{~Hz}$, like authors also do in this article, because they do not lead to significant displacement below the sleepers (they are actually filtered by the elastomeric under sleeper pads as explained in [21]).

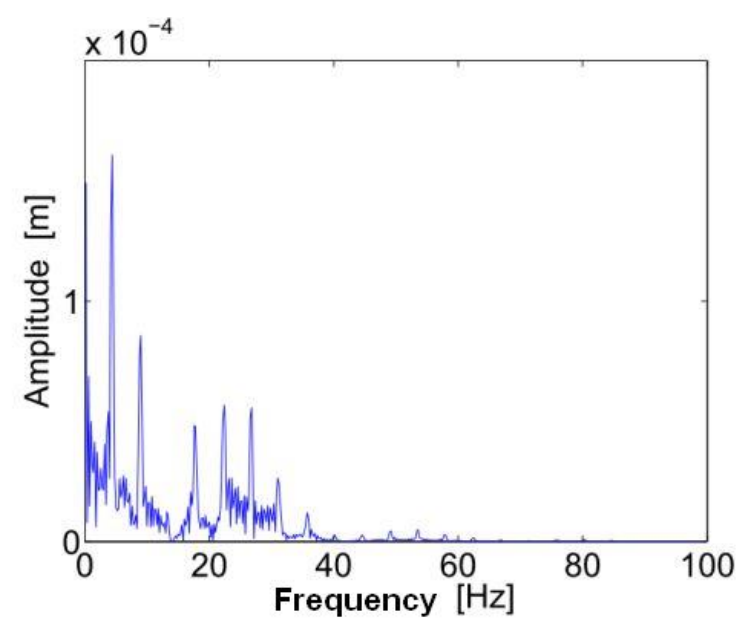

Figure 6 : Rail deflexion for a HST at $300 \mathrm{~km} / \mathrm{h}$ (after Kouroussis [8])

Table 1 gives targeted and actual values of loads used in the different cases:

Table 1 : Loading sequences characteristics

\begin{tabular}{|c|c|c|c|c|}
\hline \# loading sequence & $\mathbf{f}(\mathbf{H z})$ & $F_{\text {mean }}(\mathbf{k N})$ & targeted $\Delta F(\mathrm{kN})$ & actual $\Delta F$ \\
\hline \multirow{5}{*}{1} & 15 & \multirow{5}{*}{35} & \multirow{5}{*}{15} & 16 \\
\hline & 20 & & & 17 \\
\hline & 25 & & & 13 \\
\hline & 30 & & & 17 \\
\hline & 35 & & & 12 \\
\hline \multirow{7}{*}{2} & 5 & \multirow{7}{*}{55} & \multirow{7}{*}{35} & 35 \\
\hline & 15 & & & 36 \\
\hline & 20 & & & 35 \\
\hline & 25 & & & 28 \\
\hline & 28 & & & 36 \\
\hline & 30 & & & 37 \\
\hline & 35 & & & 27 \\
\hline
\end{tabular}

\subsection{Data acquisition}

For each sensor (see Figure 3, Figure 4 and Figure 5), for a given loading sequence and frequency, a sample of 100 loading cycles is recorded. The mean value of variation amplitude during these 100 cycles is then considered as the experimental value corresponding 
to the amplitude of dynamic response, for each sensor. Detailed characteristics of sensors are available in [24] while verification and acquisition of the measures are detailed in [21]. 


\section{Analysis of the experimental results}

The following results are presented in frequency domain. Each point represents the amplitude of the sinusoidal signal given by the corresponding sensor, assuming the established harmonic regime is reached. Experimentally, this is valid when the output signal starts to be periodic.

Sensors within the embankment (located as described in 2.2) gave results for the two loading sequences. Since $F_{\text {mean }}$ as well as the actual $\Delta \mathrm{F}$ for each frequency are different from one loading sequence to another, it is worth rescaling the results in order to compare them.

\subsection{Linearity hypothesis}

Since the actual load magnitude depends on the loading sequence (as presented in Table 1), experimental results have been rescaled (linearly) to correspond to an equivalent amplitude $\Delta \mathrm{F}=35 \mathrm{kN}$.

Figure 7 shows the rescaled incremental tensile force in reinforcement \#36 at different frequencies and the rescaled incremental vertical displacement at interface between backfill and subgrade layer. 

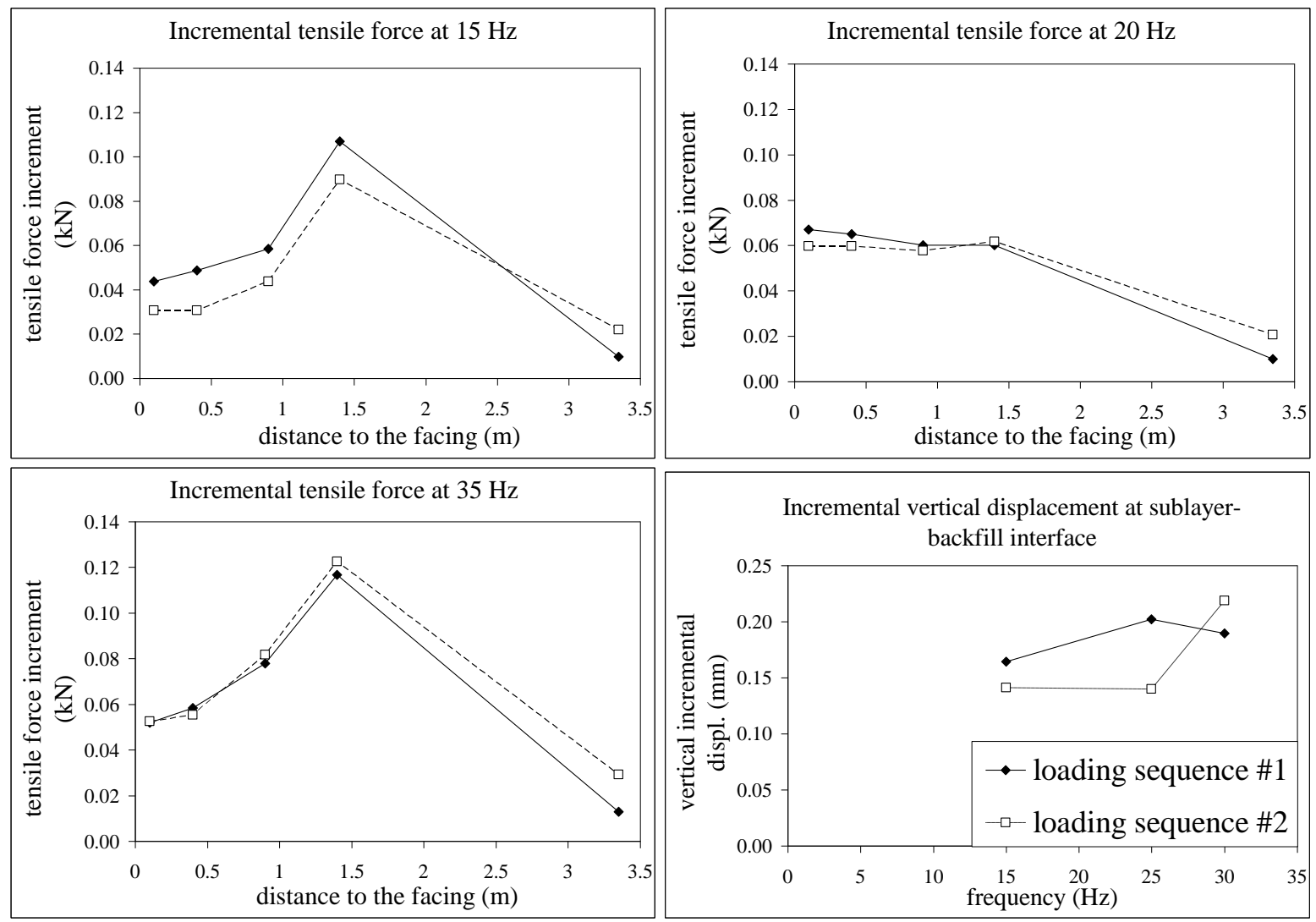

Figure 7 : Comparison of incremental tensile forces in strip \#36 and displacements at sublayer-backfill interface for both loading sequences

As shown in Figure 7, rescaled tensile force increments spectra as well as vertical displacements at subgrade/backfill interface globally present similar values for both loading sequences.

The results indicate that tensile forces in the strips as well as vertical displacements values at the top of the backfill do not depend on the mean static load (55 kN vs. $35 \mathrm{kN}$ ). Moreover, these results also indicate that dynamic response of the reinforced embankment depends linearly on the amplitude of the applied dynamic load.

This has been not observed for the vertical displacement immediately below the ballast, which means that this material does not have a linear behavior even for a small range of loading amplitude variation: this point is discussed in 3.2.1.

Horizontal facing displacements have only been measured for loading sequence \#2, but following the conclusion above, it can be assumed that they show a linear variation with the dynamic increment of load.

Finally the re-scaling process of the results validates the assumption that the behavior of the structure is linear with respect to the applied load (except for the ballast layer), which 
makes it possible to compare the variations of experimental values with frequency distributions, regardless of the loading sequence or the actual $\Delta \mathrm{F}$.

\subsection{Computation of vertical displacements from accelerations data}

\subsubsection{Presentation}

Due to the difficulty of inserting displacements sensors within the bulk (see 1.2) only few experimental values have been obtained for the vertical displacements. However, acceleration sensors collected much more data. Since this article is focused on the behavior of the structure under monofrequential load in harmonic steady state, the results given by the accelerometer have been used to derive the amplitude of the displacement, from the frequency and the amplitude of the vertical acceleration. More sophisticated methods are available (as presented for example in [25]) but there are not pertinent here, because the problem here only concerns small harmonic variations in linear domain.

Acceleration sensors are model FA-101 from FGP company. They have a 2\% constructor precision in the $0-300 \mathrm{~Hz}$ range of frequency and have been satisfyingly tested for accelerations from 0 to $\pm 10 \mathrm{~g}$. More details on calibration and data sampling are available in [24]. The comparison between computed and monitored displacements is available in Figure 8. Please note that acceleration sensors and LVDT sensors are actually distant of $10 \mathrm{~cm}$ (see Figure 2).

\subsubsection{Results}

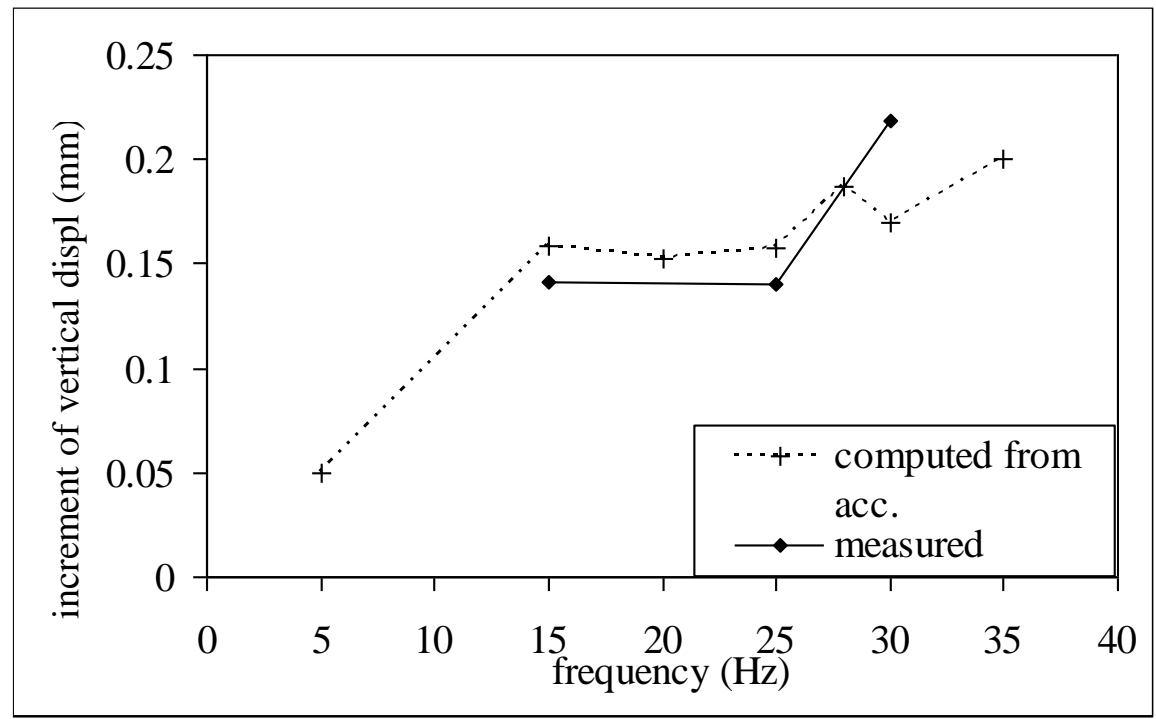

Figure 8 : Vertical displacements at backfill/sublayer interface for loading sequence \#1 
The results shown in Figure 8 indicate a good agreement between measured displacements and displacements computed from measured accelerations.

A comparison between measured and computed-from-acceleration vertical displacements at the ballast-sublayer interface has also been performed. The results were there not in good agreement to each other. A possible explanation is the coarse-grained structure of ballast which may give rise to strong differences between the accelerations and displacements at points close to each other (see 3.2.1).

\subsubsection{Conclusion}

The good agreement between measured and computed-from-acceleration displacements gives the opportunity to use acceleration data to compute displacements at frequencies where no displacements measurements are available. It also allows having a better confidence in LVDT measurements values. Again, the consistency between measured and computed from acceleration displacements has been found to be valid only within the backfill and not in the ballast layer.

\subsection{Complementary results}

An easy way to represent the dynamic behavior of the experimental embankment is to study the response of the different sensors in the frequency domain (analysis of the spectrum). Then, it is possible to find some dynamic characteristics of the embankment such as its resonance frequency, its amplification magnitude and to predict what would be the answer of such structure under HST loading, especially in terms of additional tensile force in the reinforcement strips, displacements of the facing or settlement of the railway.

Consequently, as explained in 2.1, rescaled incremental sensor responses are plotted at different frequencies. Part of these results is already given in [21], but here one can focus specially on frequency dependence of displacements, stresses and reinforcement tensile force at different points within the embankment.

In the curves shown below, response of sensors is almost always plotted for dynamic loading on the sleeper placed on the MSE structure, but in some cases, the results obtained for loads applied on the sleeper above the classical embankment are also available.

Whenever possible, dynamic results are compared with static ones. As the static part of the load is taken equal to $55 \mathrm{kN}$, comparisons are made with the static $60 \mathrm{kN}$ load, which 
provides a value for a frequency equal to $0 \mathrm{~Hz}$. This makes it possible to compute the dynamic amplification coefficient of each measured field.

Spectrum of the tensile force increment in strip \#36, the facing horizontal displacements and the vertical stress at sublayer backfill interface are shown in Figure 9 to Figure 12. In order to get a good estimation of the global behavior of the reinforced structure, spectrum of mean horizontal displacements of the facing as well as the mean tensile force in armature \#36 are shown, respectively in Figure 11 and in Figure 13. Note that in Figure 10, the values corresponding to $5 \mathrm{~Hz}$ do not seem consistent with global traction distribution: this frequency will not be considered in the following.

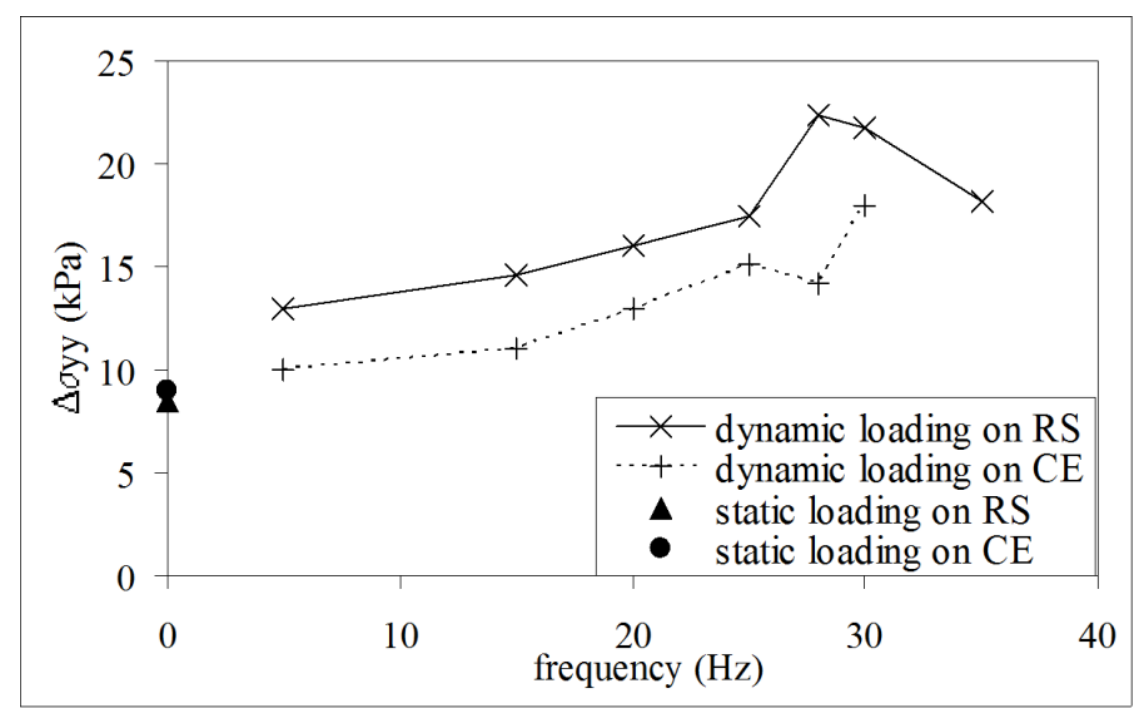

Figure 9 : Spectrum of vertical stress increment at sublayer/backfill interface and right below the sleeper

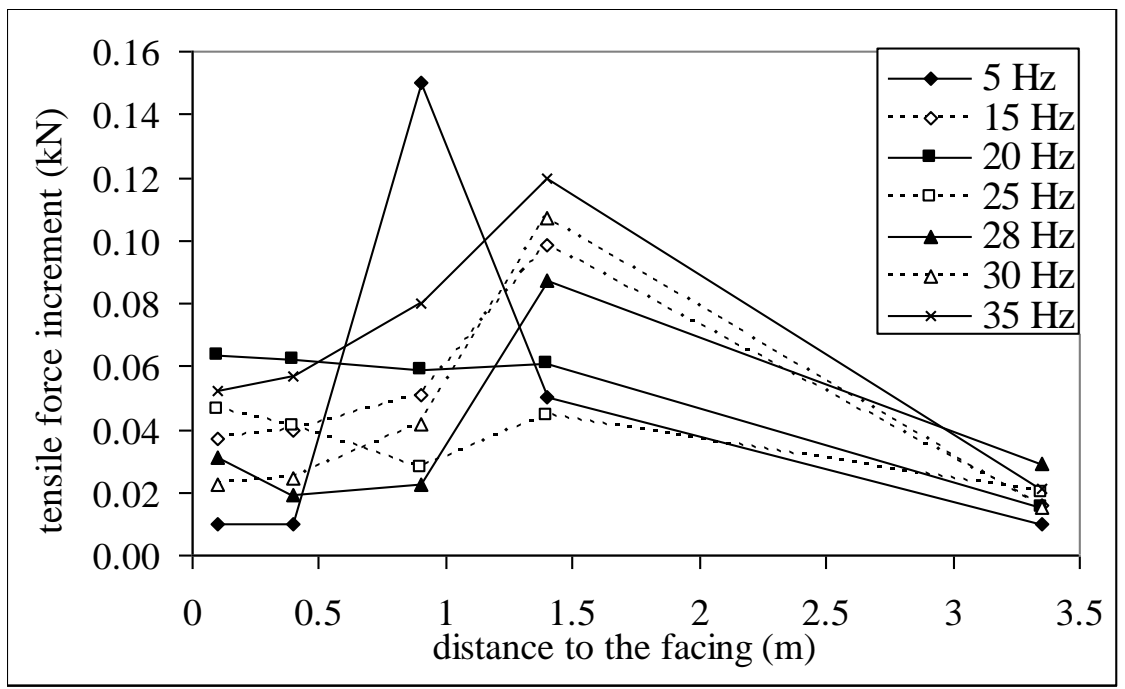

Figure 10 : Tensile force increment in reinforcement \#36 for loading on the sleeper above the classical embankment 


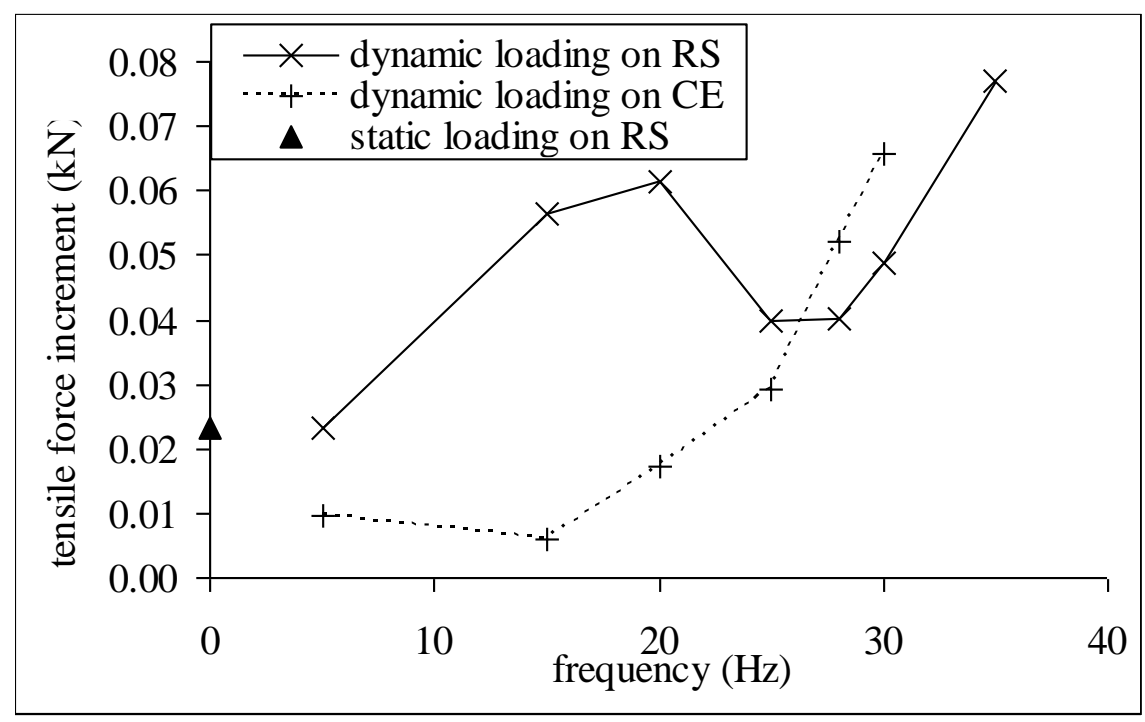

Figure 11 : Mean tensile force on the first $1.5 \mathrm{~m}$ of the strip \#36 for a loading above the reinforced structure. (Value at $0.9 \mathrm{~m}$ for $5 \mathrm{~Hz}$ not taken into account)

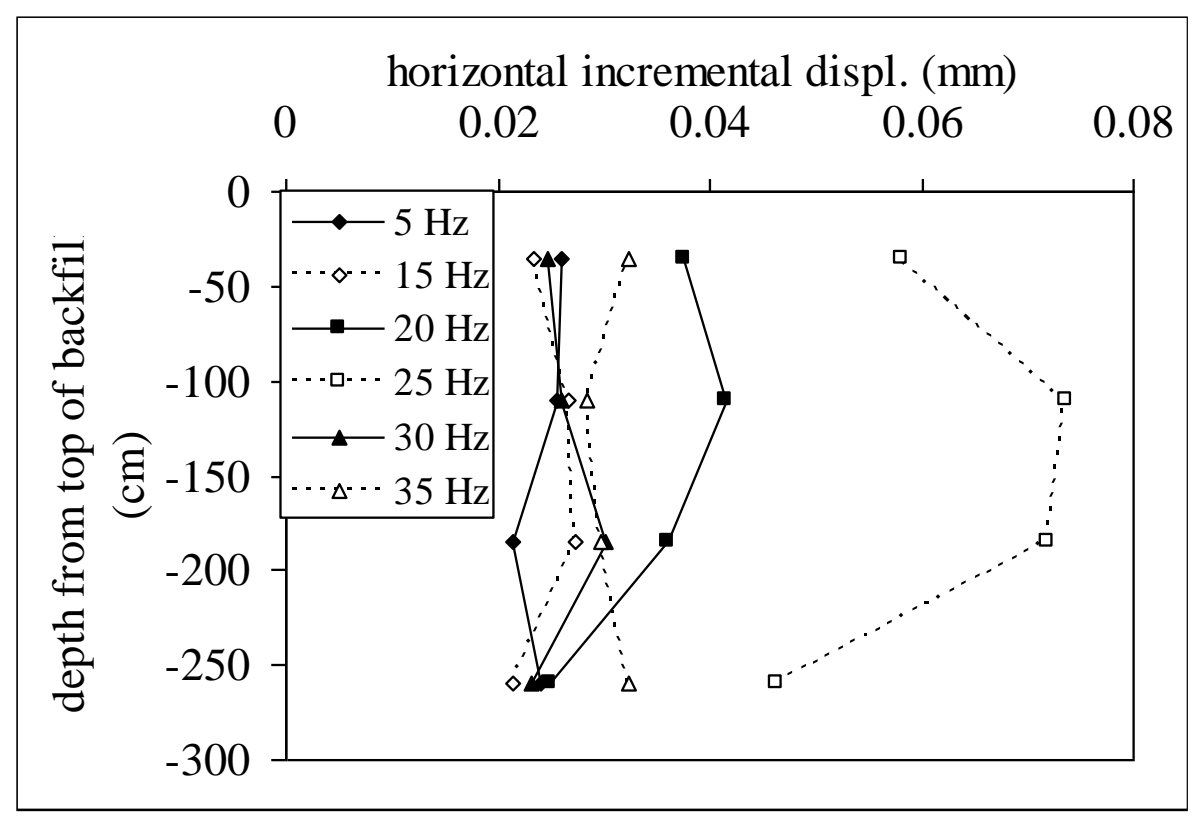

Figure 12 : Horizontal displacements of the facing 


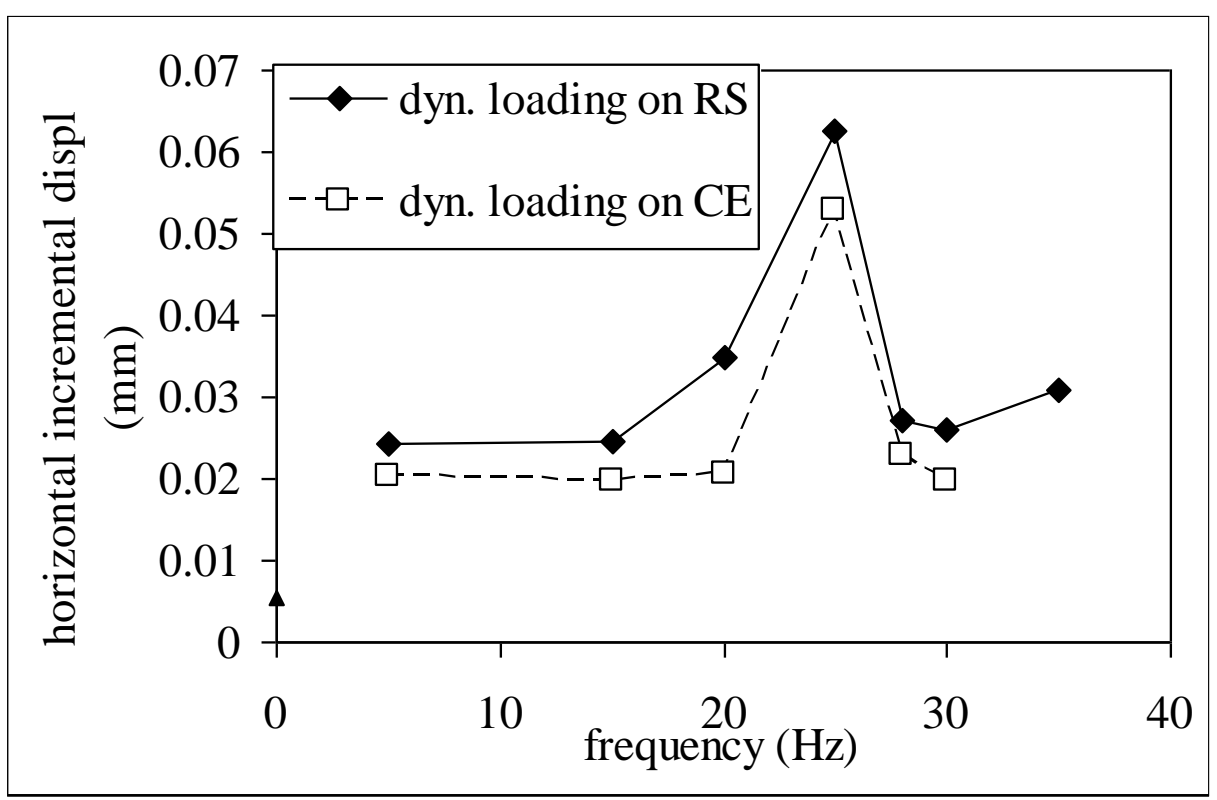

Figure 13 : Mean horizontal facing displacement of the top $2.6 \mathrm{~m}$

Note that following material parameters listed in Table 4, the wavelength for both compressive $\left(\lambda_{P}\right)$ and shear $\left(\lambda_{S}\right)$ waves into the embankment material are in the ranges given in Table 2, for each frequency.

Table 2: Wavelengths in the backfill material

\begin{tabular}{|c|c|c|c|c|c|c|c|}
\hline $\mathbf{f}(\mathbf{H z})$ & $\mathbf{5}$ & $\mathbf{1 0}$ & $\mathbf{1 5}$ & $\mathbf{2 0}$ & $\mathbf{2 5}$ & $\mathbf{3 0}$ & $\mathbf{3 5}$ \\
\hline $\boldsymbol{\lambda}_{\mathrm{P}}(\mathbf{m})$ & $62.3-86.6$ & $31.2-43.3$ & $20.8-28.9$ & $15.6-21.7$ & $12.5-17.3$ & $10.4-14.4$ & $8.9-12.4$ \\
\hline $\boldsymbol{\lambda}_{\mathrm{S}}(\mathbf{m})$ & $33.3-46.3$ & $16.7-23.2$ & $11.1-15.4$ & $8.3-11.6$ & $6.7-9.3$ & $5.6-7.7$ & $4.8-6.6$ \\
\hline
\end{tabular}

In earthquake engineering, a simple criterion to assess resonance of a single layer is when the loading frequency reaches the natural frequency of the layer, i.e. when $\lambda_{s}=4 \mathrm{H}$, with $\mathrm{H}$ the thickness of the backfill material. Here, the $25 \mathrm{~Hz}$ resonance does not correspond to this equality, because the problem is clearly different than earthquake condition, with strong 3D feature.

\subsection{Analysis of the amplification factor}

\subsubsection{Stresses}

Experimental data of stresses is only available at the top of the backfill bulk $(10 \mathrm{~cm}$ below the backfill/sublayer interface). As shown in Figure 9, a resonance seems to appear for a frequency in the range $28-30 \mathrm{~Hz}$. The amplification factor compared to static case is roughly equal to 2.5 . 


\subsubsection{Tensile forces}

A strong frequency dependency is highlighted, as shown in Figure 10 and Figure 11. The tensile force amplitude in the first $1.5 \mathrm{~m}$ depends on the frequency and also on the loaded sleeper. In both cases, tensile forces in strip \#36 present an amplification coefficient up to roughly 2.5 times the equivalent static tensile force, for the range of studied frequencies. No clear resonance frequency is highlighted. In other words, strips can present significant variations in tensile forces under dynamic loading, even for a load applied on the nearby classical embankment. This behavior is certainly due to resonance phenomena within the whole embankment but no simple explanation on the shapes of these curves can be given. Nevertheless, that may mean that the localization of the maximum of the incremental tensile force may be shifted along the reinforcement, depending on the frequency loading, and regardless of the loaded sleeper. Note however that the incremental tensile force within the strips remains very small compared to the tensile force in these strips at the end of the embankment construction, which is in the order of $5 \mathrm{kN}$ [21].

\subsubsection{Displacements}

Horizontal facing displacements are shown in figures Figure 12 and Figure 13 while vertical ones are shown in Figure 8. It can be noticed that horizontal displacements present roughly a 2.5 times amplification for a frequency equal to $25 \mathrm{~Hz}$.

The amplitude of these incremental displacements, even at resonance, does not excess $0.06 \mathrm{~mm}$ which is almost insensitive from a backfill stability point of view.

\subsubsection{Concluding remark}

An analysis of the amplification factor for tensile forces, stresses and displacements have been performed. It clearly shows that those fields are strongly dependant to the loading frequency. But no simple behavior with unique mode or resonance frequency can be highlighted, as the embankment is a heterogeneous 3D system, and as the loading is located. For facing displacement for example, it may be possible than other modes exists at higher frequencies, but those will probably less excited as the main frequencies of the HST signal stay under $35 \mathrm{~Hz}$. 


\subsection{Study of the damping ratio}

The variations of the experimental horizontal displacement with frequency allow deriving the damping ratio in the embankment, under assumption that it behaves in this direction as a one-dimensional damped oscillator.

Two different methods may be used [26] to get the damping ratio $\xi$. They are both based on the knowledge of the amplification factor. The first one consists in directly comparing horizontal displacement increment at $0 \mathrm{~Hz}$ (static case) and at resonance:

$$
2 \xi=\frac{u_{\max }}{u_{\text {stat }}}
$$

According to Figure 13, this leads to a damping ratio $\xi=4.4 \%$.

The second technique consists in estimating the bandwidth of the experimental Frequency Response Function (FRF). To do this, an analytical FRF has been fitted as well as possible to the experimental horizontal displacement values (called u) as shown in Figure 14 . The best fit is obtained for a resonance frequency of $24.5 \mathrm{~Hz}$ and a damping ratio $\xi$ of $9 \%$.

Thus, one gets a range of damping ratio under in situ condition. which is useful to choose a numerical value for the FEM model (see part 3.2.2). The difference in the damping ratio estimation given by the two different methods is because the experimental values do not fit perfectly with the chosen FRF.

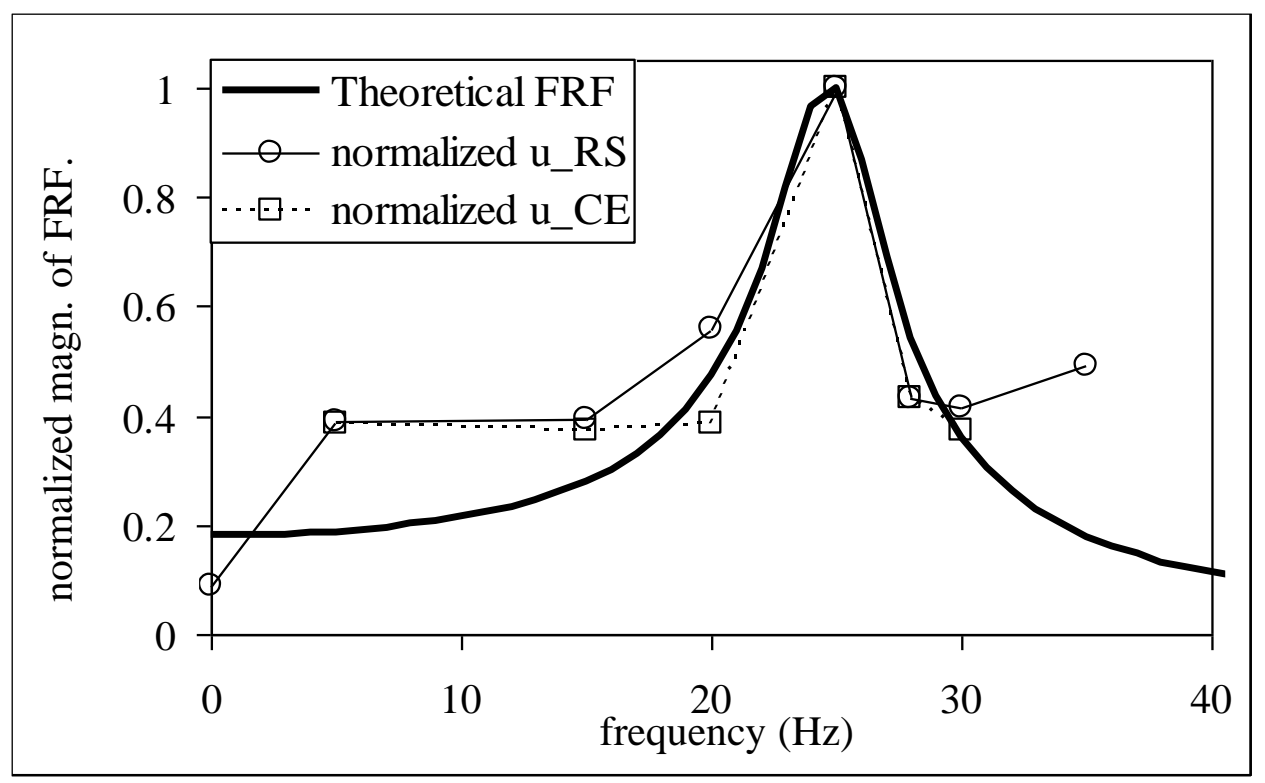

Figure 14 : Theoretical frequency response function vs. experimental mean horizontal facing displacements 


\section{Numerical model}

\subsection{Procedure description}

The full test described in part 1 is numerically modeled using the finite element code Cesar-LCPC. This code has been developed by IFSTTAR (the French Institute of science and technology for transport, development and networks) since the 1980's. A general overview of its functionalities and applications in geotechnical and civil engineering can be found in [27]. One of the software modules is dedicated to the computation of the dynamic response of a structure subjected to dynamic loads by direct integration (see [28]). The code solves the familiar problem :

$$
[M]\{\ddot{U}(t)\}+[C]\{\dot{U}(t)\}+[K]\{U(t)\}=\{P(t)\}
$$

where $\mathrm{K}, \mathrm{M}$ and $\mathrm{C}$ are the stiffness matrix, the mass matrix and the damping matrix, while $\{U(t)\},\{\dot{U}(t)\},\{\ddot{U}(t)\}$ denote the nodal values of the displacement, the velocity and the acceleration respectively. $\{P(t)\}$ represents the applied loads.

The numerical solution is based on the Newmark algorithm [29], with parameters chosen to get unconditional stability. This numerical integration scheme also entails a numerical dissipation which tends to attenuate the high frequency modes [30].

As the aim of the model is to correctly give the incremental response of the embankment under dynamic harmonic loading, it is decided to model neither the embankment construction nor the static part of the loading detailed in part 1.3.

The initial displacements, velocities and accelerations are set to zero, then a harmonic force is applied on the sleeper over a number of cycles large enough to reach a harmonic solution (10 cycles considered here).

\subsection{Assumptions}

In order to find a simple numerical model of the full scale test, one chooses linear visco-elastic constitutive laws for each material so that the response of the model, for a chosen frequency, is linear with loading amplitude, which is consistent with the analysis of the experimental results performed in part 2.

All the parameters of this model are described in the sections below. 


\subsubsection{Material properties}

One chooses every material parameter assuming they do not vary in the range of the studied frequencies.

In the case of the ballast and sublayer, elastic parameters can be taken from literature [1] and [22]. Modeling ballast as a linear visco-elastic continuum leads to a strong simplification compared with the real behavior of this material, especially under dynamic loading, as shown by many authors (for instance [3], [4] or [8]). This simplification is acceptable in so far as the analysis of the numerical results is restricted to the response of the embankment rather than the ballast layer.

The backfill material model is the major component of the full embankment, and the dynamic response of the whole structure is then closely linked to its behavior. The choice of the material properties of this material takes into consideration laboratory tests were performed on a material similar to that used in the experimental embankment. The tests have been carried out under various static loads and available in [31]. Given that the full scale embankment has been dynamically loaded, it is important to compare the confining pressure as well as the range of strain in the case of the experiment and in laboratory conditions, as summarized in Table 3.

Table 3 : Estimation of the backfill material Young Modulus based on different experimentations

\begin{tabular}{|c|c|c|c|c|}
\hline & $\begin{array}{c}\text { Confining } \\
\text { pressure (kPa) }\end{array}$ & $\begin{array}{c}\text { Deviatoric } \\
\text { pressure (kPa) }\end{array}$ & $\begin{array}{c}\text { Mean } \\
\text { deformation }\end{array}$ & $\begin{array}{c}\text { Resulting } \\
\text { E (MPa) }\end{array}$ \\
\hline $\begin{array}{c}\text { Laboratory tests } \\
\text { (Triaxial tests, } \\
\text { static loading) }\end{array}$ & $50-100-150$ & $\begin{array}{c}\text { Varying } \\
\text { between } 0 \text { and } \\
300 \mathrm{kPa}\end{array}$ & $2.0 \times 10^{-3}$ & 117 \\
\hline $\begin{array}{c}\text { Experiment } \\
\text { (dynamic loading) }\end{array}$ & $\begin{array}{c}\text { Estimated } 40 \mathrm{kPa} \\
\text { at the base of the } \\
\text { embankment } \\
\text { (from earth } \\
\text { pressure) }\end{array}$ & $\begin{array}{c}\text { Estimated } 50 \\
\mathrm{kPa} \\
\left(\mathrm{K}_{0} \text { conditions) }\right.\end{array}$ & $4.0 \times 10^{-5}$ & $\begin{array}{c}\text { To be } \\
\text { estimated }\end{array}$ \\
\hline
\end{tabular}

In the case of the CER experiment, the confining pressure at the base of the embankment has been estimated as a result of the earth pressure with density values shown in Table 4. It is then possible to get an estimation of the Young's modulus in condition of dynamic loading, at least at the embankment base. As the mean deformation is in two orders of magnitude less than in the laboratory condition, the in-situ Young's modulus at the base of the embankment was, in a first step, taken equal to $300 \mathrm{MPa}$. A final numerical calibration of 
this parameter considering the actual geometry (under the assumptions detailed below) led to a value of $290 \mathrm{MPa}$, finally used in the numerical model.

Moreover, in the numerical simulations, the Young's modulus of backfill is varying with depth to take into account the actual earth pressure as well as confining pressure coming from the embankment self-weight. The depth-dependent Young's modulus is chosen following equation (3). (after Janbu, [32])

$$
E=E_{0}(1+\kappa \sqrt{z})
$$

$\mathrm{E}_{0}$ is chosen so that at the base of the embankment $(\mathrm{z}=3.5 \mathrm{~m}), \mathrm{E}$ is equal to the previously estimated value $\mathrm{E}=290 \mathrm{MPa}$ and $\kappa$ is taken equal to $1 \mathrm{~m}^{-1 / 2}$.

Equation (3) is finally linearly approximated as shown in Figure 15.

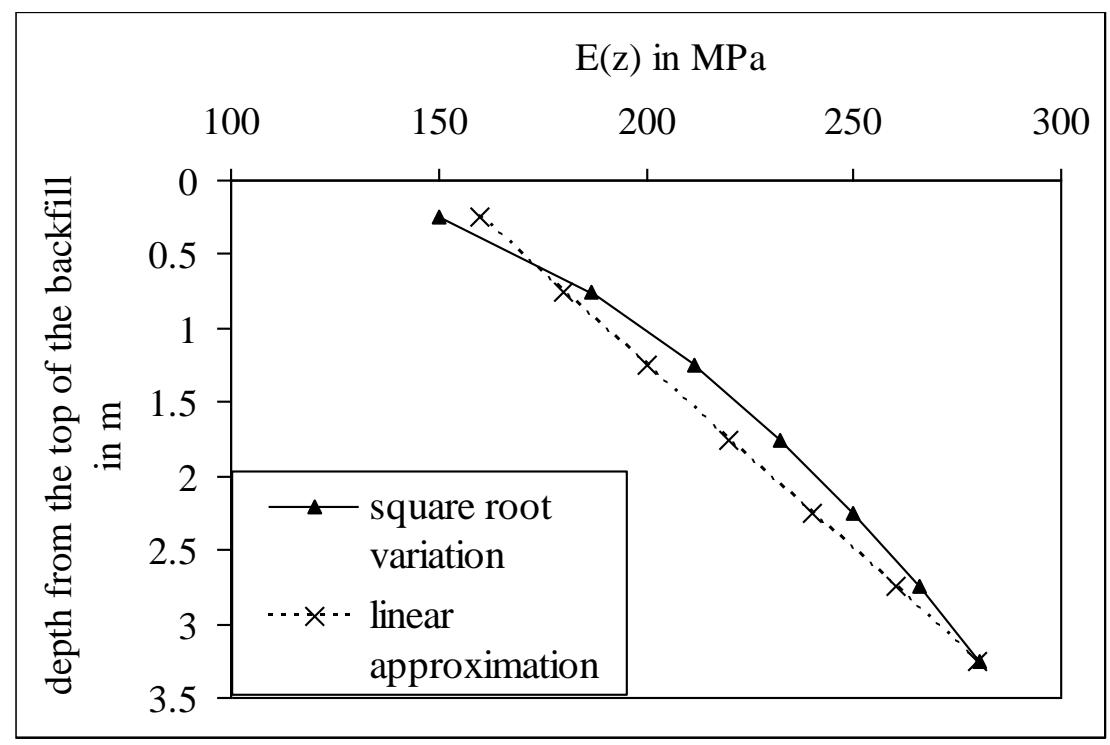

Figure 15 : Variation of backfill Young Modulus with depth

Based on equation (3) and its linearization shown in Figure 15, the expression of $\mathrm{E}$ (in $\mathrm{MPa}$ ) used in the numerical model becomes, with $\mathrm{h}$ the backfill bulk height in meter and $\mathrm{z}$ the depth from the top of it, in meter:

$$
E=290-40(h-z)
$$

Regarding the facing panels, the introduction of interface elements between panels (or other similar numerical procedures) is avoided by modeling the facing as a continuum with an elastic transverse isotropic constitutive law (same parameters in directions $\mathrm{Y}$ and $\mathrm{Z}$, as shown in Table 4 : Material elastic parameters). Such a constitutive law makes it possible to consider 
a realistic modulus in the vertical direction together with a reduced flexural stiffness in the facing plane. However, with this simplifying assumption, the facing behaves as a continuum and not as an assembly of panels.

Considering these assumptions, parameters are chosen as following: $E_{y}$ and $E_{z}$ are chosen ten times smaller than $E_{x}$ to take into account the presence of rubber wedges between concrete panels. The shear behavior in a plane containing the unit vector $e_{x}$ is described by means of a specific shear modulus $G$. The choice of this parameter allows reducing significantly the elastic restoring force due to facing flexion, which makes the model more consistent with the actual behavior of the facing made of discrete panels.

Contrary to what was done in the static case in [13], it was not needed to model the interface between facing and embankment backfill, because only incremental displacements under dynamic loading are investigated and they do not imply differential settlement between facing and embankment.

The other material parameters are taken from [13] and [21] and given in Table 4:

Table 4 : Material elastic parameters

\begin{tabular}{|c|c|c|c|c|c|c|c|}
\hline & $\gamma\left(\mathbf{k N / \mathbf { m } ^ { 3 } )}\right.$ & $\mathbf{E}(\mathbf{M P a})$ & $\boldsymbol{v}(-)$ & $\mathbf{V}_{\mathbf{p}}(\mathbf{m} / \mathbf{s})$ & $\mathbf{E}_{\mathbf{x}}(\mathbf{M P a})$ & $\begin{array}{c}\mathbf{E}_{\mathbf{y}}=\mathbf{E}_{\mathbf{z}} \\
(\mathbf{M P a})\end{array}$ & $\mathbf{G}(\mathbf{M P a})$ \\
\hline Ballast & 17 & 60 & 0.2 & 198 & - & - & - \\
\hline Sublayer & 23.3 & 90 & 0.3 & 228 & - & - & - \\
\hline Sleeper & 25 & $2.5 \times 10^{4}$ & 0.2 & 3333 & - & - & - \\
\hline Backfill material & 20.8 & $150-290$ & 0.3 & $312-433$ & - & - & - \\
\hline Reinforcement strips & - & $2.1 \times 10^{5}$ & - & - & - & - & - \\
\hline Reinforcement connection & - & $1.48 \times 10^{5}$ & - & - & - & - & - \\
\hline Facing wall & 25 & - & 0.2 & - & $2.5 \times 10^{4}$ & $2.5 \times 10^{3}-$ & $1.0 \times 10^{7}$ \\
\hline
\end{tabular}

\subsubsection{Damping}

Damping has been taken into consideration in the computation using Rayleigh model [26]: the global damping matrix is a linear combination of the global mass matrix (with coefficient $\alpha$ ), and the global stiffness matrix (with coefficient $\beta$ ). Then the whole structure has the same damping coefficient. Coefficients $\alpha$ and $\beta$ are chosen to get a damping ratio $\xi$ of $5 \%$. As harmonic loads only are applied to the structure, the exact values of such coefficients can be taken for each frequency as detailed in Table 5), following equation (5) (from [26]). The values of $\alpha$ and $\beta$ are set for each frequency to the whole model, to ensure the damping ratio value is exactly equal to $5 \%$ and then to avoid making approximation on this parameter. 


$$
\xi=\frac{1}{2}\left[\frac{\alpha}{\omega}+\beta \omega\right]
$$

Table 5 : Numerical values of Rayleigh damping coefficients

\begin{tabular}{|c|c|c|c|c|}
\hline $\mathbf{f}(\mathbf{H z})$ & $\omega(\mathrm{rad} / \mathrm{s})$ & $\alpha(\mathrm{rad} / \mathrm{s})$ & $\beta$ (s/rad) & $\xi(\%)$ \\
\hline 5 & 31.42 & 3.09 & \multirow{9}{*}{$4.77 \times 10^{5}$} & \multirow{9}{*}{5} \\
\hline 10 & 62.83 & 6.09 & & \\
\hline 15 & 94.25 & 9.00 & & \\
\hline 20 & 125.66 & 11.81 & & \\
\hline 25 & 157.08 & 14.53 & & \\
\hline 28 & 175.93 & 16.12 & & \\
\hline 30 & 188.50 & 17.15 & & \\
\hline 35 & 219.91 & 19.68 & & \\
\hline 40 & 251.33 & 22.12 & & \\
\hline
\end{tabular}

\subsubsection{Reinforcement model}

Reinforcements are modeled using bar elements while the surrounding backfill is represented by volume elements, both kinds of elements having nodes in common.

Preliminary computations have been done, considering same displacements for the reinforcement and the surrounding soil (no interface behavior). These computations led to incremental tensile forces within the reinforcements much larger than the experimental values. Then it has been decided to use a so-call frictional bar model, in order to model more precisely the interface behavior. This frictional bar model takes into consideration a possible differential displacement between a node of the soil and the previous related node of the reinforcement. This differential displacement is linked to the tensile force within the reinforcement strip by the mean of a supplementary parameter, called $\mathrm{C}^{\mathrm{I}}$, which refers to the soil-inclusion interface stiffness. The full model allows also considering failure criteria, which will not be used here, as it is chosen to perform the full numerical analysis in the elastic domain. The full description of this model is available in [13].

Since no experimental data are available to calibrate this parameter, it is given a value in the same order of magnitude as the similar parameters in [13] or [33]: the interaction coefficient $\mathrm{C}^{\mathrm{I}}$ is taken equal to $10 \mathrm{MN} / \mathrm{m}^{4}$.

Reinforcement strips are connected to the facing panels using some special steel connection pieces. While reinforcement bars elastic properties are well known (from [10], [21], see Table 4), connection pieces are actually softer than reinforcement [34], which must be taken into account in the numerical model. 


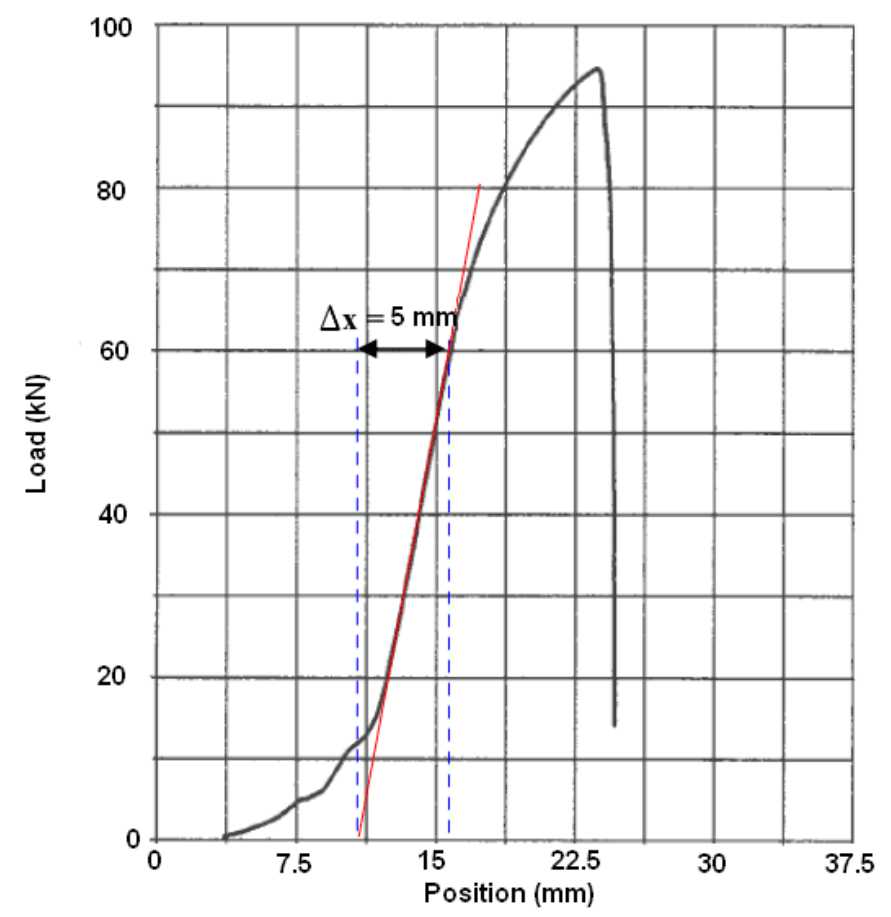

Figure 16 : Estimation of the equivalent stiffness of the connection (after Bennani, [34])

Figure 16 provides an estimation of the stiffness of connection elements. On the basis of these results, it has been chosen to take the Young modulus of the connection element equal to $14.8 \mathrm{GPa}$ (12 times softer than the strip). From a numerical point of view, these connections are taken as the geometrical extension of bars within the facing.

\subsubsection{Mesh}

The whole experimental embankment has been represented by an equivalent 3D meshed volume. The ground, facing, ballast layer, sublayer and sleepers were represented by a total of around 31,100 quadratic elements (15-nodes triangular prisms) for 47,000 nodes.

Special care has been taken to select mesh size, in order to ensure correct waves propagation into the modeled continuum. For a maximal applied frequency of $40 \mathrm{~Hz}$, the minimum wavelength $\lambda_{\mathrm{s}}$ in the embankment is around $1.5 \mathrm{~m}$, as shown in Table 2. Following [35], the mesh characteristic size is taken as close as possible as $\lambda_{\min } / 10$. In order to ensure reasonable computation times, however, the mesh is finer for the reinforced part of the embankment and coarser for the classical embankment. The size of the elements varies between $10 \mathrm{~cm}$ near the sleepers and $1.6 \mathrm{~m}$ at the bottom of the classical embankment, as shown in Figure 17. 
The reinforcements strips are located on a $10 \times 5$ grid defined by y $\in\{0.55 ; 1.45 ; 2.05 ; 2.95$; $3.55 ; 4.45 ; 5.05 ; 5.95 ; 6.55 ; 7.45\} ; \mathrm{z} \in\{0.37 ; 1.12 ; 1.87 ; 2.26 ; 3.37\}$. Each strip is $3.5 \mathrm{~m}$ long along the $x$-direction and discretized in nine 3-nodes friction bar elements.

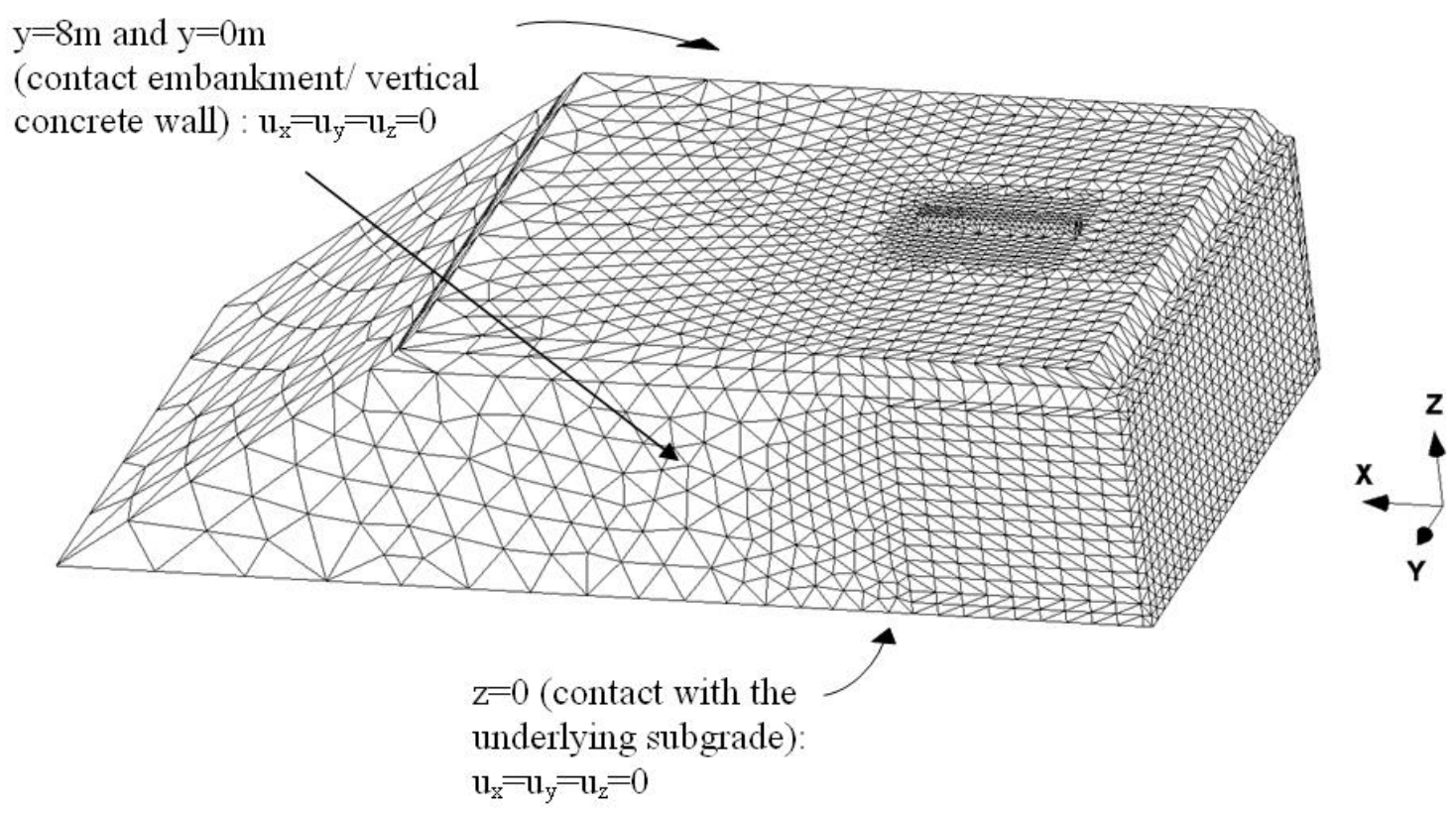

Figure 17 : Mesh and boundaries conditions

\subsubsection{Boundary conditions}

The boundary conditions consist of setting all displacements in every direction equal to zero for the bottom, the right and the left side of the structure (Figure 17). It has been assumed that lateral walls as well as the soil underneath are infinitely rigid and the friction in each direction at those interfaces is enough to restrain any displacements, which is in agreement with experimental observations. This also avoids the use of numerical procedures such as boundary elements or absorbing layers (a full description of the available techniques is presented in [26]) to take into account a potential transmission of waves into the surrounding space, which would lead to higher complexity of the model and a larger number of elements. Although this set of boundary conditions tends to simplify the numerical procedure, this choice has been verified by performing numerical parametric studies, in order to estimate for example if shear displacement along concrete walls should be taken into account. Finally the presented set of boundaries conditions tends to give the most accurate answer of the modeled embankment, compared to the actual experimental behavior. 


\section{Results and discussion:}

This section presents the numerical results at the positions of sensors within the embankment. The numerical results are compared with the experimental ones, in order to assess the validity of the numerical model.

\subsection{Vertical stresses}

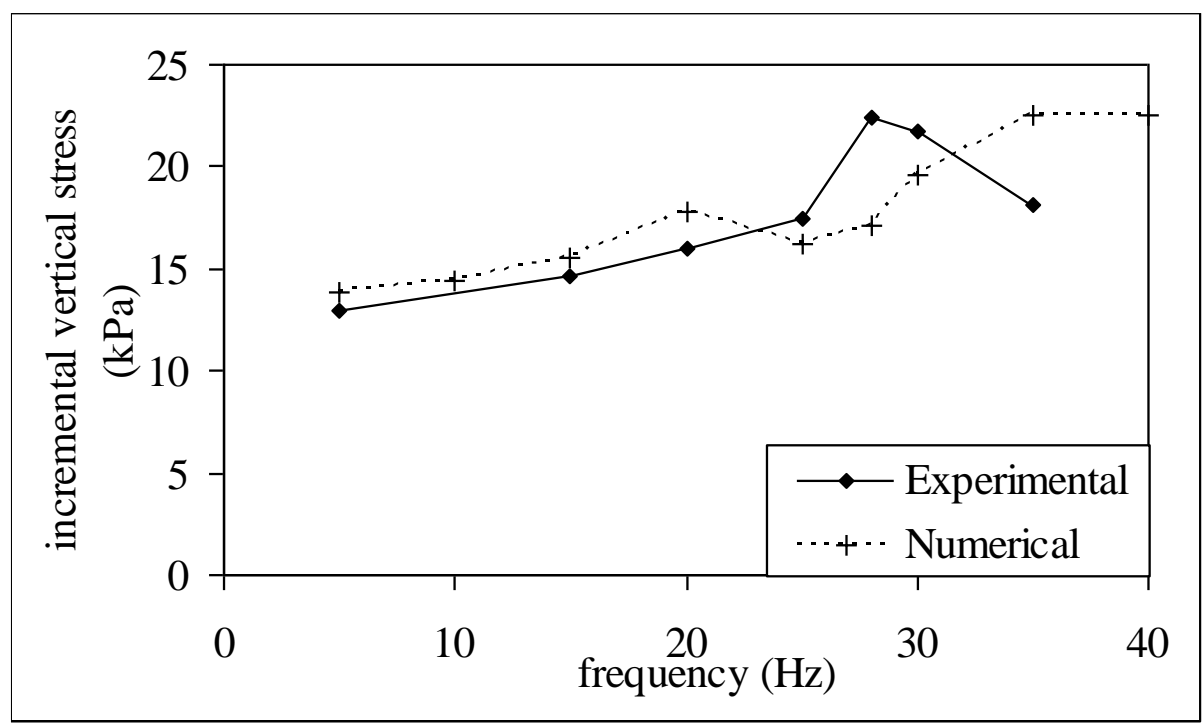

Figure 18 : Incremental vertical stress at the backfill/sublayer interface

Figure 18 compares the computed vertical stresses with the experimental values. The resonance at $28 \mathrm{~Hz}$ which was experimentally highlighted does not appear in the numerical simulations. Nevertheless the shape of numerical curve fits globally well with the experimental one, especially in view of the facts that the numerical value of the stresses strongly depends on the location within the mesh.

\subsection{Horizontal facing displacements}




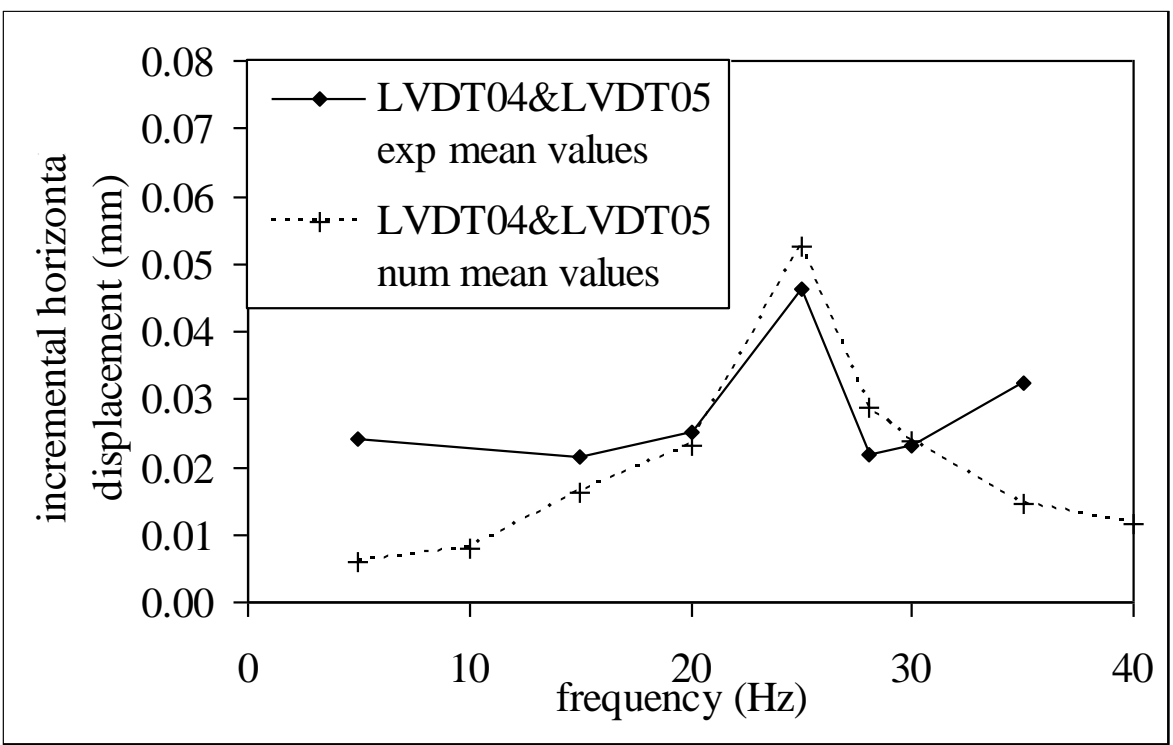

Figure 19 : Incremental horizontal displacement of the facing at $1.5 \mathrm{~m}$ from the base of the wall

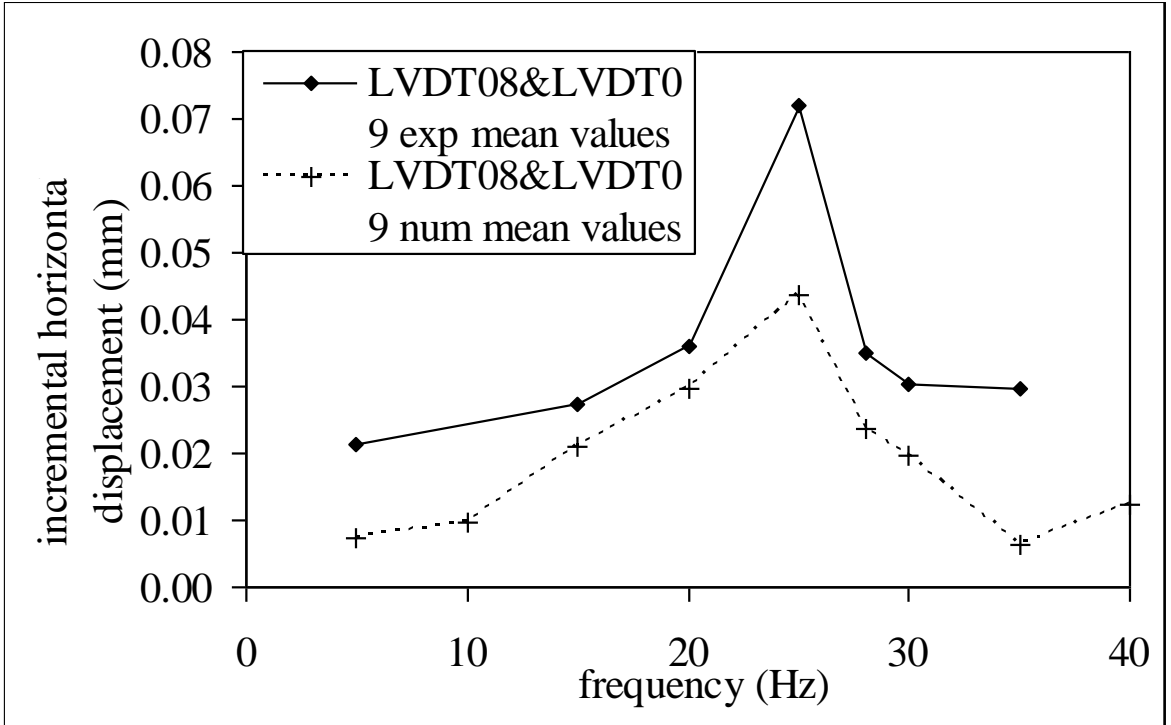

Figure 20 : Incremental horizontal displacement of the facing at $2.25 \mathrm{~m}$ from the base of the wall 


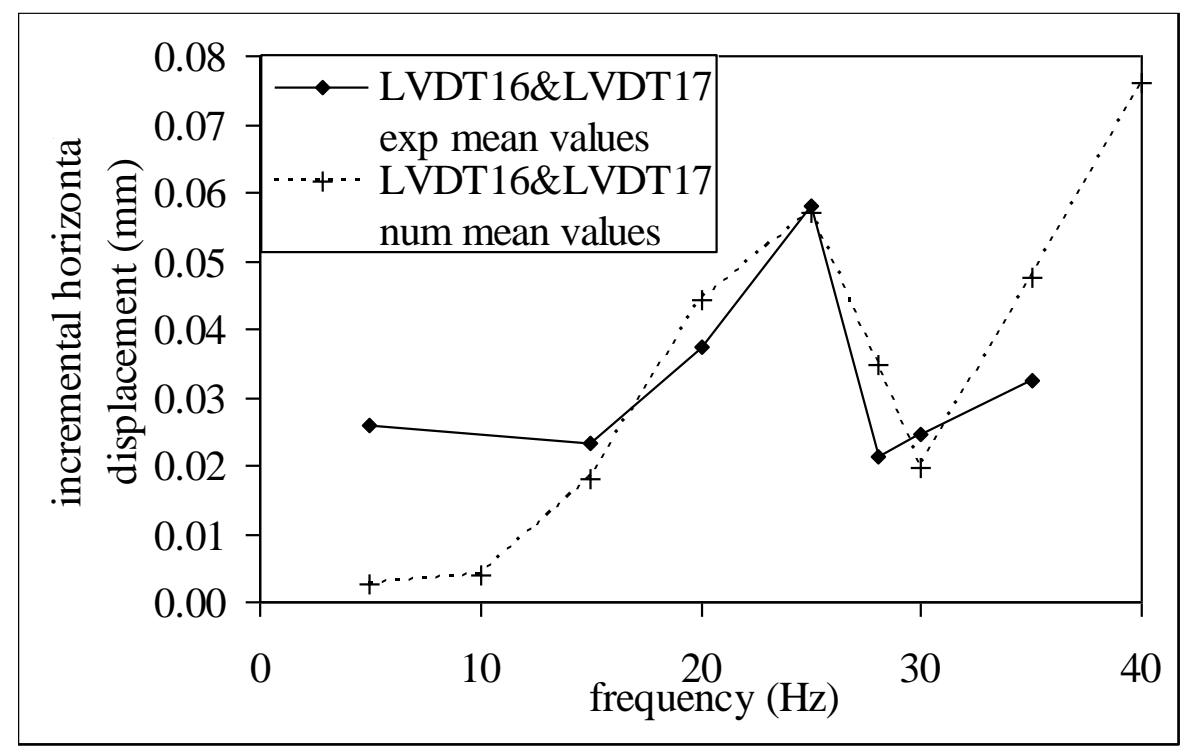

Figure 21 : Incremental horizontal displacement of the facing at the very top of the wall

Numerical and horizontal incremental facing displacements are compared at different heights in figures Figure 19 to Figure 21. Despite facing has been modeled as a continuum while the actual wall behaves as discrete concrete panels, numerical results fairly agrees with experimental measurements. From a spectral point of view, the resonance frequency, the bandwidth as well as the global shape of the curves given by the model are close to the experimental ones, even if the model underestimates the horizontal displacements of the wall at $2.25 \mathrm{~m}$ height.

\subsection{Vertical displacements at the backfill-sublayer interface}

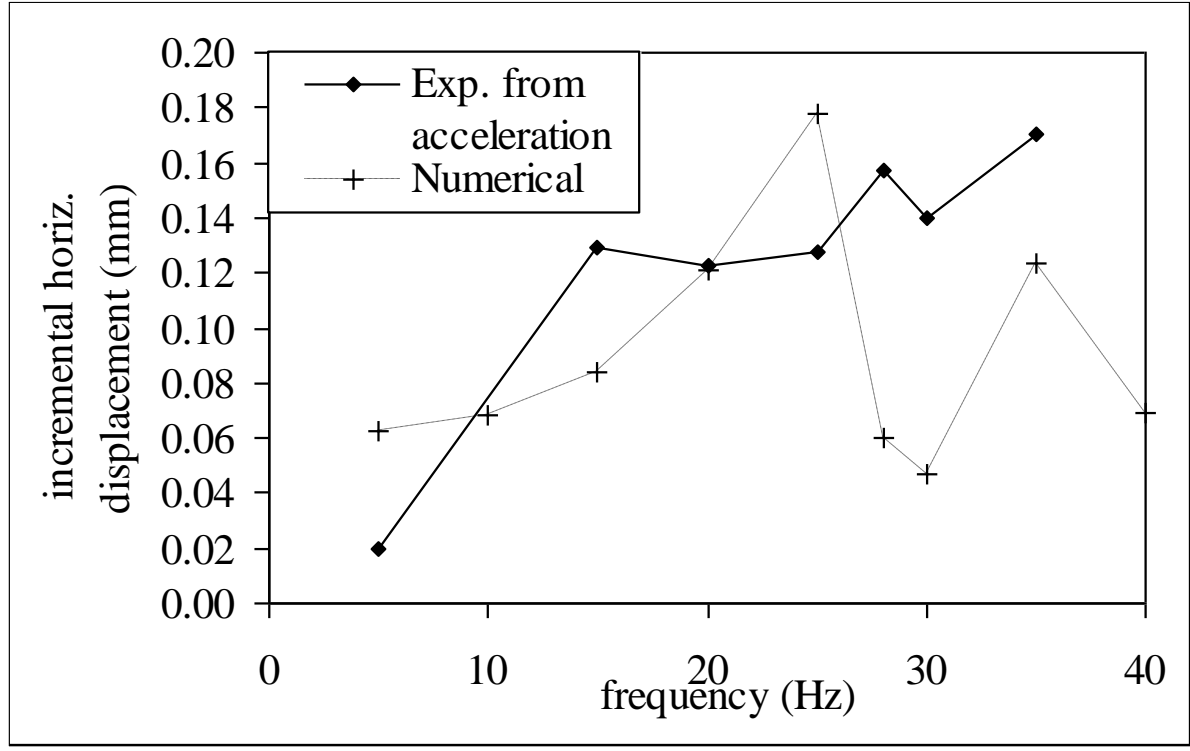

Figure 22 : Incremental vertical displacement at the backfill/sublayer interface 
Figure 22 shows that computed vertical displacements have the same order of magnitude than the experimental ones. But, despite some numerical parametric tries (not exposed in detail in this article), it has not been possible to reproduce numerically the displacements spectra obtained experimentally. A possible explanation of the differences between numerical model and experimental results could be the linearization of the backfill Young's modulus (Figure 15), which may lead to an overestimation of the modulus in the top of the backfill. However, this approximation is not likely to explain the difference between the shapes of the curves. It is also possible that the difference between both curves is due to the casing used to place the LVDT sensor (see Figure 4), which has not been modeled. The localization of this casing can actually locally modify the wave structure, leading to numerically misestimating the displacement in this area.

\subsection{Incremental tensile force distribution along the strips}

Incremental tensile forces along the strip \#46 (whose position is shown in Figure 3) are presented in figures Figure 23 to Figure 27.

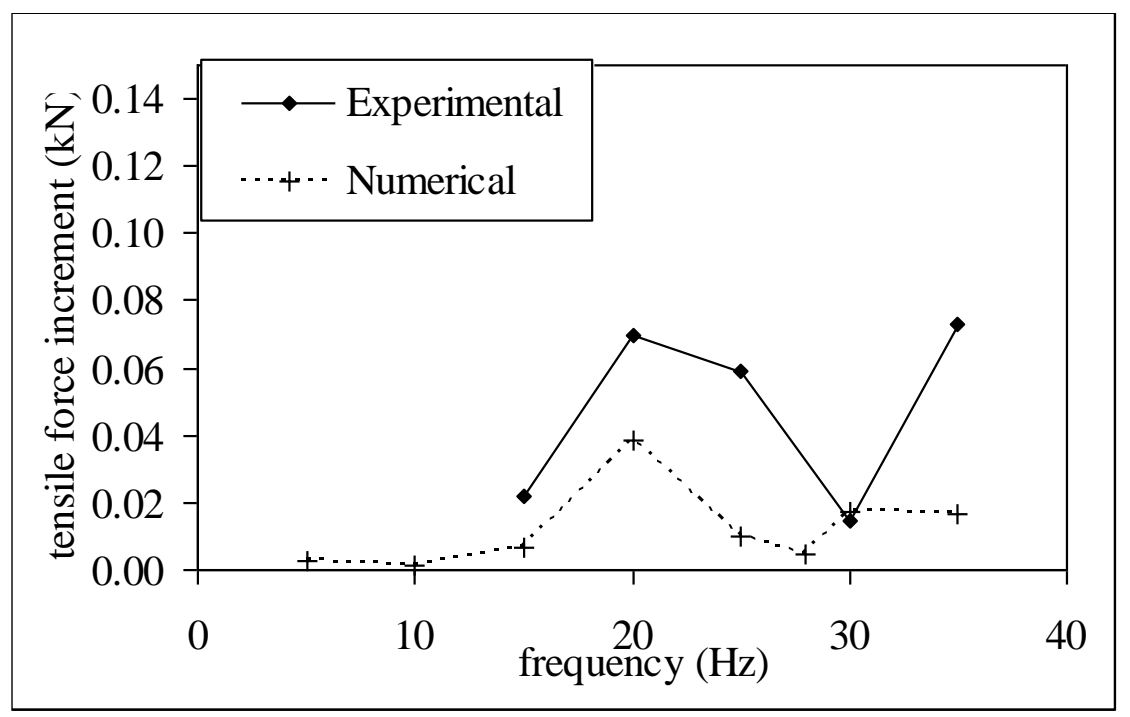

Figure 23 : Incremental tensile force in strip \#46, at $0.1 \mathrm{~m}$ from the facing 


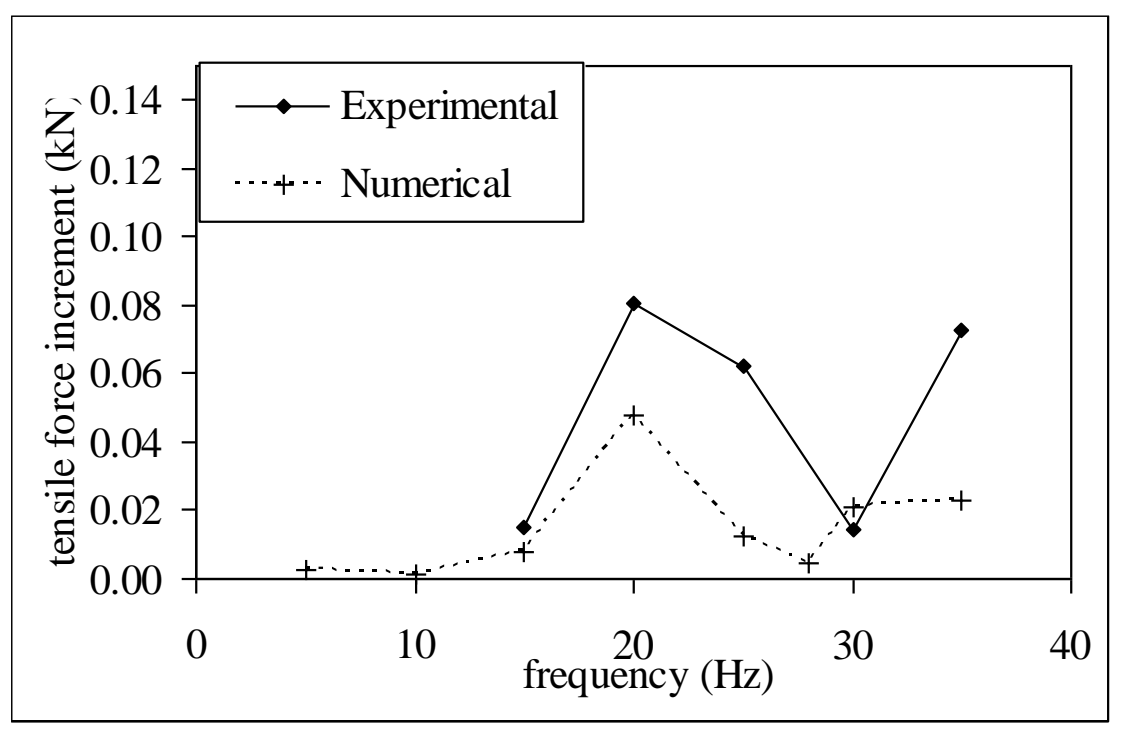

Figure 24 : Incremental tensile force in strip \#46, at $0.4 \mathrm{~m}$ from the facing

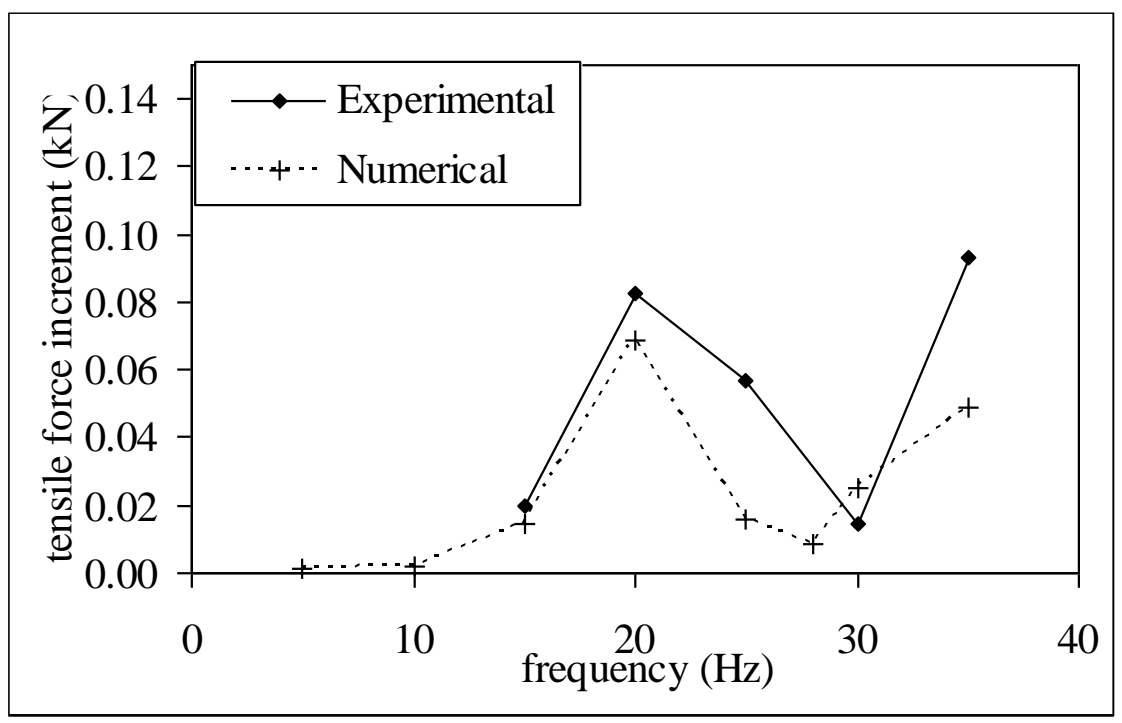

Figure 25 : Incremental tensile force in strip \#46, at $0.9 \mathrm{~m}$ from the facing 


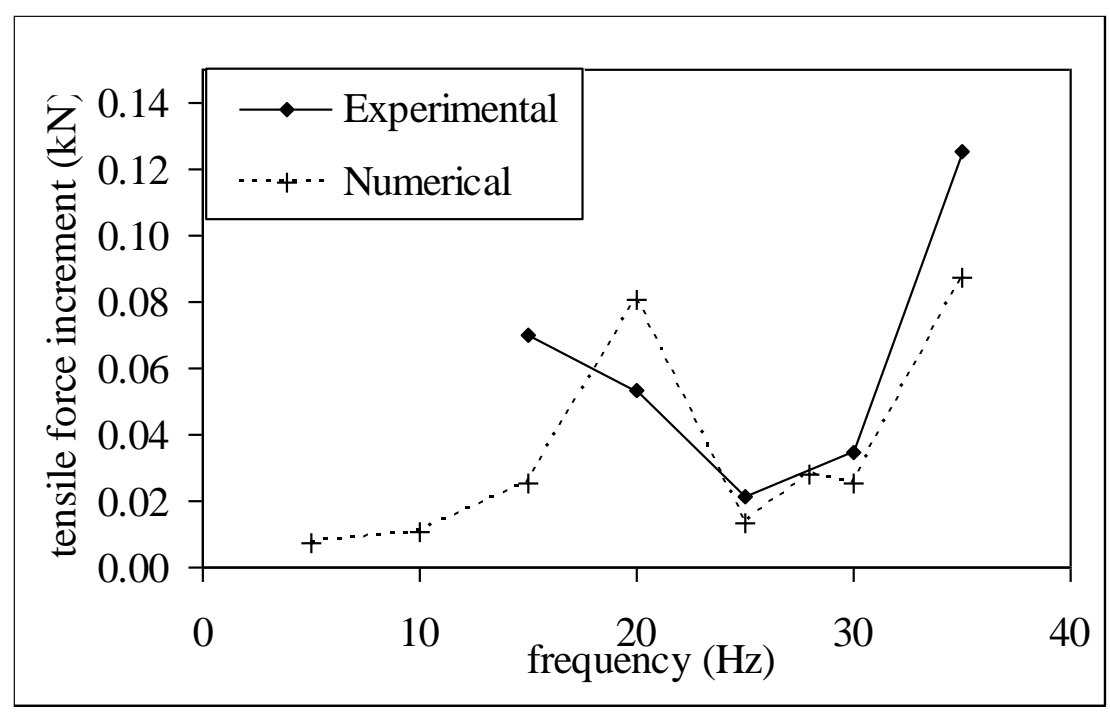

Figure 26 : Incremental tensile force in strip \#46, at $1.4 \mathrm{~m}$ from the facing

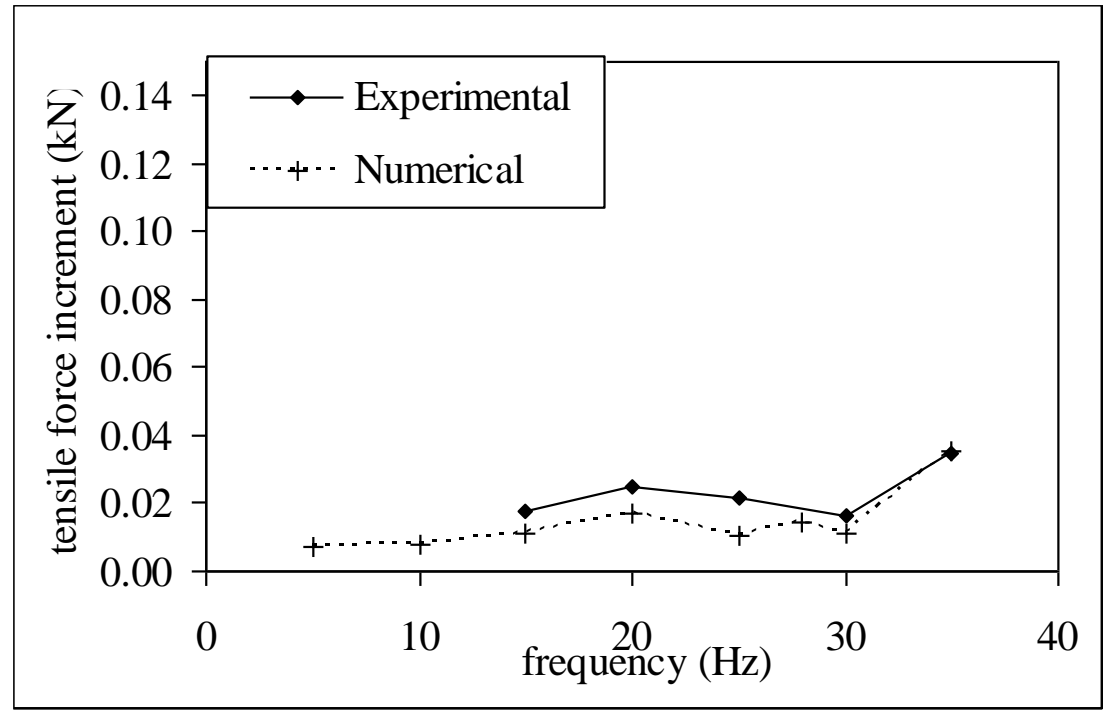

Figure 27 : Incremental tensile force in strip \#46, at $3.35 \mathrm{~m}$ from the facing

The shape of the numerical spectra is in good agreement with experimental spectra, while the magnitude of tensile forces given by the model is quite close to the experimental ones. Only in the very beginning of the strip, the model tends to underestimate the actual tensile force by a factor 2 on average of the spectra. Nevertheless these results are very satisfying under the assumptions made, and especially considering the fact that the computation has been performed in the time domain and not directly in the frequency domain, as explained in part 1.3.

Numerical incremental tensile force values in strip \#36 presents similar frequencydependence as experimental ones. But it has not been possible to get exactly the same results, 
as the numerical model tends to overestimate the tensile force increment, compared with real values.

\subsection{Incremental vertical stress distribution}

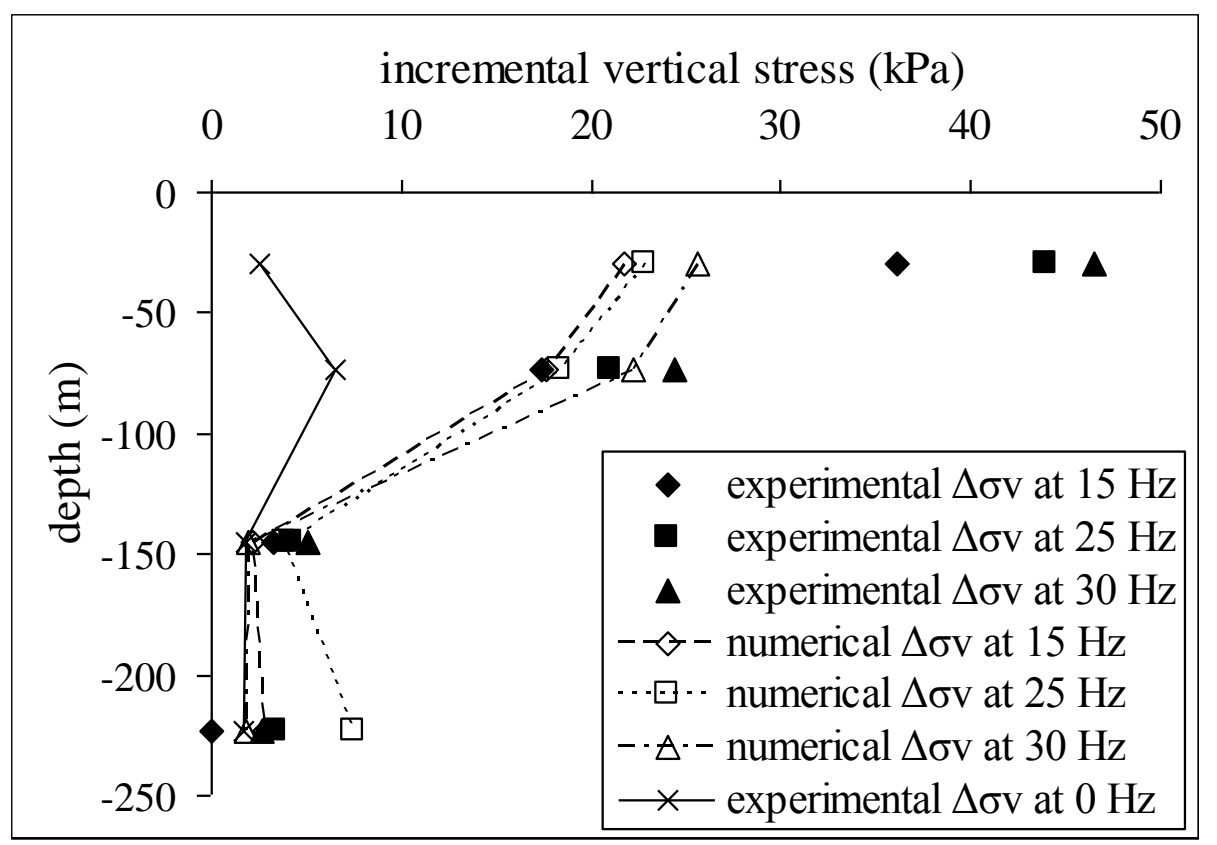

Figure 28 : Comparison between experimental and numerical incremental stresses at different frequencies

Figure 28 shows the experimental and numerical increments of vertical stresses, compared with stresses measured under a $35 \mathrm{kN}$ static loading $(0 \mathrm{~Hz})$.

These incremental vertical stresses are computed, on the basis of the experiment, by comparing the maximum attained stress during the dynamic load to the in situ stress measured during a static $55 \mathrm{kN}$ load. Using the hypothesis of linearity justified in part 2.1, one can derive the value of the increment of stress caused by dynamic amplitude variation. Stresses relative to a $35 \mathrm{kN}$ static loading have been directly measured by sensors [21].

Experimental vertical stresses values coming from sensors located close to the ballast are subjected to interpretation, because of the high heterogeneity of the material itself, and the rearranging of grains from a loading sequence to another. Nevertheless, the model fits well with the experimental data for levels deeper than ballast-sublayer interface: magnitude, as well as frequency dependence is well predicted by the model. Experimental and numerical data show that the increase of stress due to dynamic loading is concentrated at the top of the reinforced structure, and the dynamic variation of confining pressure around reinforcement strips will only affect the first and second reinforcement layers (located at $75 \mathrm{~cm}$ and $150 \mathrm{~cm}$ of depth). 
It can also be noticed that stress distribution depends on the frequency, but the shape of the stress-depth distribution curve is similar for all frequencies.

\subsection{Synthesis}

The model gives good predictions of the horizontal displacements spectrum at different depths, as well as vertical stress at sublayer/backfill interface.

It gives accurate order of magnitude in terms of vertical displacements, but the spectrum obtained numerically differs from the experimental one. This may be caused by the casing borehole used to insert displacement sensor.

The proposed model gives satisfying results for tensile force increments in strip \#46. In strips \#36 results are less satisfactory.

On the whole, the agreement between measurements and simulations is relatively good, given the assumptions made to keep the model simple and to avoid the introduction of too many parameters :

- in the first place, the reinforcement-ground interface stiffness has been taken the same for each layer (cf part 3.2.3), which may be the strongest assumption of the model, as this parameter actually depends on several complex phenomenon, such as local confining pressure, restrained dilatancy, etc... A special analysis of this local interface phenomenon will be the task of a future article.

- the choice of global damping values (cf part 3.2.2) also plays a role on the numerical values of tensile forces in reinforcements.

- in the last place, one can question the influence of the choice of a continuous wall to model the facing panels (cf part 3.2.1), and of the boundary conditions on the dynamic response of the model.

Figure 28 clearly shows that the dynamic loading directly affects the vertical stress applied on the strips for the first and second level of reinforcements, and the inertia terms cannot be neglected. It also shows that the numerical model is able to reproduce accurately this stress variation, in term of magnitude and frequency dependency.

Finally, the proposed 3D model is found to be acceptable, since it has been compared with real measurements data in different points. Moreover, since all data have been compared in the frequency domain, it can be advocated that the model is able to give the time-response of each chosen parameter, in each point of the considerer $3 \mathrm{D}$ geometry. It will be then 
possible to numerically predict more specific time-dependent behavior, such as transient regime or free oscillations of the system after the passing of a HST. 


\section{Conclusion and perspectives}

In this article, an experiment on a full-scale MSE embankment under dynamic loading in harmonic steady state is presented and discussed. Experimental results have been presented and three dimensional finite element computations have been performed. Stresses in the bulk, facing displacements and tensile forces during the loading have been sampled. Experimental results indicate a strong frequency dependency of the response of the embankment to harmonic loading, for a constant force amplitude.

A 3D-numerical analysis has been performed to investigate the response of the wall to harmonic loading. Effects of the construction of the embankment or of fatigue under high number of cycles are not taken into account. To keep the model as simple as possible, simple visco-elastic constitutive laws have been used to simulate geomaterials behavior. The key points of the model are the variation of the backfill Young modulus with depth, the use of a transverse isotropic elastic constitutive law to model the facing as a continuum, the use of a so called "friction bar" model to model steel strips, and finally the computation performed using direct-integration solver. The proposed model fits fairly well with the experimental spectra, in term of stresses, horizontal facing displacements, as well as for tensile forces in first reinforcement layer. The frequency dependency as well as the magnitude of amplification is satisfactorily reproduced by the model.

The good agreement between the model and the measures makes it possible to use this model to get accurate predictions of the behavior of reinforced embankments under HST loading. Especially, it will be possible to focus on the influence of the strips on behavior of the embankment. It will be also possible to better model the facing as well as the loading, in order to simulate a real passing HST. 


\section{References}

[1] NGI., 2005. Sustained performance of railway track (SUPERTRACK) - final report; <www.supertrack.no/reports>.

[2] SNSEE., 2005. Sustained performance of railway track (SUPERTRACK) final report 1 track measurements in Beugnâtre, <www.supertrack.no/reports>.

[3] Alves-Fernandes, V., Costa D’Aguiar, S., 2013. Development of a non-linear ballasted railway track model. Proceedings of the $18^{\text {th }}$ International Conference on Soil Mechanics and Geotechnical Engineering, Paris 2013.

[4] Nguyen, V.H., 2002. Comportement dynamique de structures non-linéaires soumises à des charges mobiles. PhD, Ecole des Ponts ParisTech. (in French)

[5] Woodward, P.K., El Kacimi, A., Laghrouche, O., Medero, G., Banimahd, M., 2012. Application of polyurethane geocomposites to help maintain track geometry for high-speed ballasted railway tracks. Journal of Zhejiang University-Science A (Appl Phys \& Eng) 13 (11), 836-849.

[6] Müller-Boruttau, F.H., Breitsamter, N., 2001. Elastic elements reduce the load exerted on the permanent way. IMB Dynamik.

[7] Verbraken, H., Lombaert, G., Degrande, G., 2012. Experimental and numerical prediction of railway induced vibration. Journal of Zhejiang University-Science A (Appl Phys \& Eng) 13 (11), 802-813.

[8] Kouroussis, G., 2009. Modélisation des effets vibratoires du traffic ferroviaire sur l'environnement. PhD faculté Polytechnique de Mons. (in French)

[9] Bastick, M., Schlosser, F., Segrestin, P., Amar, S., Canepa, Y., 1993. Experimental reinforced earth structure of Bourron-Marlotte: slender wall and abutment test. Comptes Rendus du Colloque Renforcement des sols : expérimentations en vraie grandeur des années 80, Paris, pp. 201-228.

[10] Abdelouhab, A. Dias., Freitag, N., 2010. Physical and analytical modeling of geosynthetic strip pull-out behaviour. Geotextiles and Geomembranes 28, 44-53.

[11] Chau, T.L., Bourgeois, E., Corfdir, A., 2011. Finite element analysis of the effect of corrosion on the behavior of reinforced earth walls. International Journal for Numerical and Analytical Methods in Geomechanics, DOI: 10.1002/nag.1095. 
[12] Bourgeois, E., Soyez, L., Le Kouby, A., 2011. Experimental and numerical study of the behavior of a reinforced earth wall subjected to a local load. Computers and Geotechnics 38 (4), 515-525.

[13] Bourgeois, E., Le Kouby, A., Soyez, L., 2012. Influence of the strip-backfill interaction model in the analysis of the behavior of a mechanically stabilized earth wall. Soils and Foundations. DOI: $\underline{10.1016 / j . s a n d f .2012 .05 .012}$

[14] Bennani, Y., Soyez, L., Freitag, N., 2013. Interpretation of pullout tests of high adherence steel reinforcements in a Reinforced Earth structure under a cyclic dynamic loading. Proceedings of the $18^{\text {th }}$ International Conference on Soil Mechanics and Geotechnical Engineering, Paris 2013.

[15] Ling, H., Liu, H., Kaliakin, V., Leshchinsky, D., 2004. Analyzing Dynamic Behavior of Geosynthetic-Reinforced Soil Retaining Walls. J. Eng. Mech., 130(8), 911-920.

[16] Wolfe, W.E., Rea, D., 1978. The Effect of Vertical Motion on the Seismic Stability of Reinforced Earth Walls. Proceeding of the symposium on earth reinforcement, ASCE, Pittsburg, pp 856-879.

[17] Hatami, K., Bathurst, R.J., 2000. Effect of structural design on fundamental frequency of reinforced-soil retaining walls. Soil Dynamics and Earthquake Engineering 19, 137-157.

[18] Cai, Z., Bathurst, R.J., 1995. Seismic response analysis of geosynthetic reinforced soil segmental retaining walls by finite element method. Computers and Geotechnics, 17(4), 523546. DOI: $\underline{10.1016 / 0266-352 X(95) 94918-G}$

[19] Ling, H., Liu, H., Mohri, Y., 2005. Parametric Studies on the Behavior of Reinforced Soil Retaining Walls under Earthquake Loading. J. Eng. Mech., 131(10), 1056-1065.

[20] Murray, R.T., Carder, D.R., Krawczyk, J.V., 1979. Pull-out tests on reinforcements embedded in uniformly graded sand subject to vibration. Design parameters in geotechnical engineering, Proceedings of the $7^{\text {th }}$ European Conference on Soils Mechanics and Foundation Engineering, Brighton, Vol. 3, pp. 115-120.

[21] Soyez, L., 2009. Contribution à l'étude du comportement des ouvrages en sol renforcé, soumis à des charges d'exploitation ferroviaire (charges dynamiques et cycliques), $\mathrm{PhD}$ Ecole des Ponts ParisTech.. (in French)

[22] SNCF, 1999. Spécifications techniques pour la fourniture de granulats utilisés pour la réalisation et l'entretien de voies ferrées, IN 0091. (in French) 
[23] Degrande, G., Schillemans, L., 2001. Free field vibrations during the passage of a Thalys High Speed Train at variable speed. Journal of Sound and Vibration

[24] Froumentin, M., Hosseingholian, M., Mercadier, D., Charles, I., 2008. Comportement des ouvrages sous charges ferroviaire - Application au cas de ouvrages de soutènement en sol renforcé et en remblai". Internal report, V2.0, CETE N-C/CER. (in French)

[25] Boore, D M; Bommer, J.J., 2005.Processing of strong-motion accelerograms: needs, options and consequences. Soil Dynamics and Earthquake Engineering, 25, pp.93-115.

[26] Semblat, J-F, Pecker, A.1999. Waves and Vibrations in Soils: Earthquakes, Traffic, Shocks,Construction works, IUSS press, pp. 283-308.

[27] Humbert, P., Dubouchet, A., Fezans, G., Remaud, D., 2005. CESARLCPC: A computation software package dedicated to civil engineering uses. Bull Lab Ponts et Chaussées 256-257, 7-37

[28] LCPC, 2006. CESAR-LCPC version standard - RÉFÉRENTIEL THÉORIQUE : Module DYNI, 6th edition, internal report, 16 p. (in French).

[29] Newmark, N. M., 1959. A method of computation for structural dynamics. J. Eng. Mech., 85(EM3), 67-94.

[30] Hughes, T. J. R., 1987. The finite element method - Linear static and dynamic finite element analysis, Prentice Hall, Englewood Cliffs, NJ.

[31] Reiffsteck, P., Arbaut, J., Sagnard, N., Khay, M., Subrin, D., Chapeau, C., Levacher, D., 2007. Laboratory measurements of the mechanical behavior of heterogeneous soils. Bull Lab Ponts Chaussées, 268-269:59-82.

[32] Janbu, N., 1963. Soil compressibility as determined by oedometer and triaxial tests. European Conference on Soil Mechanics and Foundation Engineering, Wiesbaden, Vol.1, pp. 19-25, and Vol. 2, pp. 17-21.

[33] Nguyen, V.T., 2014. Analyse sismique des ouvrages renforcés par inclusions rigides à l'aide d'une modélisation multiphasique. PhD Ecole des Ponts ParisTech. (in French)

[34] Bennani, Y., 2011. Equivalent stiffness of the connection. Internal report, Terre Armée France.

[35] Semblat, J.F., Brioist, J.J., 2009. Efficiency of higher order finite elements for the analysis of seismic wave propagation. Journal of Sound and Vibration 231, 2 (2000) 460-467, DOI: $\underline{10.1006 / \text { jsvi.1999.2636 }}$ 